OPEN ACCESS

Edited by:

Víctor Flors,

Jaume I University, Spain

Reviewed by:

Oswaldo Valdes-Lopez,

Universidad Nacional Autónoma de

México, Mexico

Paloma Sanchez-Bel,

Jaume I University, Spain

*Correspondence: Ralf Oelmüller

ralf.oelmueller@uni-jena.de

Specialty section:

This article was submitted to

Plant Microbe Interactions,

a section of the journal

Frontiers in Plant Science

Received: 04 October 2017

Accepted: 20 April 2018

Published: 08 May 2018

Citation:

Vahabi K, Reichelt M, Scholz SS, Furch ACU, Matsuo M, Johnson JM,

Sherameti I, Gershenzon J and

Oelmüller R (2018) Alternaria

Brassicae Induces Systemic Jasmonate Responses in Arabidopsis Which Travel to Neighboring Plants via

a Piriformsopora Indica Hyphal Network and Activate Abscisic Acid Responses. Front. Plant Sci. 9:626. doi: 10.3389/fpls.2018.00626

\title{
Alternaria Brassicae Induces Systemic Jasmonate Responses in Arabidopsis Which Travel to Neighboring Plants via a Piriformsopora Indica Hyphal Network and Activate Abscisic Acid Responses
}

\section{Khabat Vahabi ${ }^{1}$, Michael Reichelt ${ }^{2}$, Sandra S. Scholz ${ }^{1}$, Alexandra C. U. Furch ${ }^{1}$, Mitsuhiro Matsuo ${ }^{1}$, Joy M. Johnson ${ }^{1}$, Irena Sherameti ${ }^{1}$, Jonathan Gershenzon ${ }^{2}$ and Ralf Oelmüller ${ }^{\text {* }}$}

\footnotetext{
${ }^{1}$ Department of Plant Physiology, Matthias Schleiden Institute of Genetics, Bioinformatics and Molecular Botany, Friedrich-Schiller-University Jena, Jena, Germany, ${ }^{2}$ Department of Biochemistry, Max-Planck Institute for Chemical Ecology, Jena, Germany
}

Stress information received by a particular local plant tissue is transferred to other tissues and neighboring plants, but how the information travels is not well understood. Application of Alternaria Brassicae spores to Arabidopsis leaves or roots stimulates local accumulation of jasmonic acid (JA), the expression of JA-responsive genes, as well as of NITRATE TRANSPORTER (NRT)2.5 and REDOX RESPONSIVE TRANSCRIPTION FACTOR1 (RRTF1). Infection information is systemically spread over the entire seedling and propagates radially from infected to non-infected leaves, axially from leaves to roots, and vice versa. The local and systemic NRT2.5 responses are reduced in the jar1 mutant, and the RRTF1 response in the rbohD mutant. Information about $A$. brassicae infection travels slowly to uninfected neighboring plants via a Piriformospora Indica hyphal network, where NRT2.5 and RRTF1 are up-regulated. The systemic A. brassicae-induced $\mathrm{JA}$ response in infected plants is converted to an abscisic acid (ABA) response in the

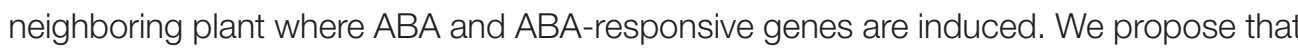
the local threat information induced by $A$. brassicae infection is spread over the entire plant and transferred to neighboring plants via a $P$. indica hyphal network. The JA-specific response is converted to a general ABA-mediated stress response in the neighboring plant.

Keywords: systemic signaling, interplant communication, REDOX RESPONSIVE TRANSCRIPTION FACTOR1, NITRATE TRANSPORTER2.5, Piriformospora indica, Alternaria brassicae, jasmonic acid, abscisic acid

Abbreviations: NRT, NITRATE TRANSPORTER; RRTF1, REDOX-RESPONSIVE TRANSCRIPTION FACTOR1; JA, jasmonic acid; ABA, abscisic acid; CMN, common mycorrhizal network; dpi, days past infection. 


\section{INTRODUCTION}

Long distance signaling and organ-to-organ communication are essential features of all plants (Huber and Bauerle, 2016). These processes allow information perceived locally to be systemically spread over the entire plant body, and integrated by regulatory networks causing non-cell autonomous responses in neighboring and systemic cells (Suzuki and Mittler, 2012; Fu and Dong, 2013; Kliebenstein, 2014). For example, after pathogen attack systemic responses can provide a memory of initial infection by priming remote leaves for enhanced defense and immunity to re-infection (Reimer-Michalski and Conrath, 2016). After colonization with beneficial root-colonizing microbes, root-to-shoot signaling and induced systemic resistance (Vlot et al., 2008) play important roles in resistance responses of the aerial parts of plants (cf. Erb et al., 2009; Pieterse et al., 2014). Numerous mobile signals have been described in these contexts. Fast information transfer is proposed to be associated with $\mathrm{Ca}^{2+}$, reactive oxygen species (ROS) and electropotential waves, and/or altered hydraulic pressure (Christmann et al., 2007; Miller et al., 2009; Zimmermann et al., 2009; Kudla et al., 2010; Swanson et al., 2011; Choi et al., 2012, 2016; Mousavi et al., 2013; Gilroy et al., 2014; Jayaraman et al., 2014; Steinhorst and Kudla, 2014; van Bel et al., 2014; Kiep et al., 2015; Hedrich et al., 2016). RNAs and miRNA propagate more slowly through the vascular tissue (Hannapel et al., 2013; Chien et al., 2017), while hormones, proteins, peptides, and small molecules also transfer specific information to distal areas on a slower scale (Dempsey and Klessig, 2012; Jimenez-Aleman et al., 2015; Lacombe and Achard, 2016). In Arabidopsis, systemic leaf-to-leaf signaling depends on direct vascular connections of local and systemic leaves, hardwired by the developmental pattern of the rosettes (Dengler, 2006; Mousavi et al., 2013; Salvador-Recatalà et al., 2014; Kiep et al., 2015).

Likewise, $\mathrm{N}$ and $\mathrm{P}$ sensing activates long-distance signaling to coordinate nutrient homeostasis (Li et al., 2014; Ma et al., 2015; Okamoto et al., 2016; Puga et al., 2017; Xuan et al., 2017). Information on the status of Fe and other important ions is systemically spread over the entire plant body (Gayomba et al., 2015). Concentration gradients inform distal tissues about metabolic changes and activate transport or signaling events along these gradients. Examples are source/sink relationships for the sugar transport through the phloem (cf. Lemoine et al., 2013), or cellular nitrate gradients that activate translocation of nitrate to nitrate-deprived tissues (cf. White et al., 2016).

Besides systemic signaling within the plant body, threat information is also translocated to neighboring plants. Volatile organic compounds (VOCs) and green leaf volatiles emitted by stress-exposed plants activate the defense machinery in neighboring plants (Arimura et al., 2000; Baldwin et al., 2002, 2006; Matsui, 2006; Niinemets et al., 2013), and the VOC blend determines the specificity of interplant communications (Ueda et al., 2012). Interplant communication is also mediated by common mycorrhizal networks (CMN), which interconnects roots of the same or different plant species (Fitter et al., 1998; Giovannetti et al., 2006; Selosse et al., 2006; Simard et al., 2012). CMNs transfer threat information, but also $\mathrm{C}, \mathrm{N}$, and $\mathrm{P}$ from one plant to another (Leake et al., 2004; He et al., 2009; Ren et al., 2013), thereby promoting plant performance, resource distribution within communities (Eason et al., 1991; Selosse et al., 2006; He et al., 2009; Barto et al., 2012) and survival of seedlings on the forest floor (Dickie et al., 2005a,b; McGuire, 2007; Teste et al., 2009; Booth and Hoeksema, 2010; Bingham and Simard, 2011, 2012). A good candidate for interplant communication is the root-colonizing endophyte Piriformospora indica because it colonizes the roots of many plant species. $P$. indica promotes plant performance by supplying nutrients and conferring resistance against biotic and abiotic stresses, similar to mycorrhizal fungi of CNN (Camehl et al., 2011; Hilbert et al., 2012; Dong et al., 2013; Harrach et al., 2013; Venus and Oelmüller, 2013; Yogawat et al., 2013; Sun et al., 2014; Ye et al., 2014; Matsuo et al., 2015).

Here, we demonstrate that Arabidopsis plants infected with A. brassicae spores distribute the information within the entire plant body and inform neighboring non-infected plants about the threat via a $P$. indica hyphal network. The information flow was monitored by measuring NITRATE TRANSPORTER2.5 (NRT2.5) and REDOX-RESPONSIVE TRANSCRIPTION FACOR1 (RRTF1) mRNA levels, since these mRNAs responded systemically to A. brassicae infection in distal leaves and roots. NRT2.5 plays an important role in nitrate acquisition and remobilization in $\mathrm{N}$-starved plants, takes part in nitrate loading into the phloem (Lezhneva et al., 2014) and together with NRT2.6 is involved in Arabidopsis growth promotion by the rhizobacterium Phyllobacterium brassicacearum STM196 (Mantelin et al., 2006; Dechorgnat et al., 2012; Kechid et al., 2013). The transporter is part of a complex with NRT2.1 which contributes to the high-affinity nitrate transport (Kotur and Glass, 2014). Nitrate transporters also function in nitrate sensing to coordinate distribution of this nutrient within the plant body (Chopin et al., 2007; Wang et al., 2012; Fagard et al., 2014; Krapp et al., 2014). The highly conserved RRTF1 induces ROS accumulation in response to abiotic and biotic stress signals, and the RRTF1 mRNA is rapidly upregulated by $\mathrm{H}_{2} \mathrm{O}_{2}$ and other ROS, as well as biotic- and abiotic-induced redox signals (Khandelwal et al., 2008; Matsuo and Oelmüller, 2015; Matsuo et al., 2015). This transcription factor also stimulates systemic ROS accumulation in distal non-treated leaves (Matsuo et al., 2015). Our data suggest that NRT2.5 and RRTF1 are good marker genes to monitor local and systemic stress responses as well as the reaction in the nontreated neighboring plants. Besides, A. brassicae induces jasmonic acid (JA) and JA-inducible genes in local and systemic tissues of infected plants and this information is converted to an abscisic acid (ABA) response and the induction of ABA-responsive genes in neighboring plants via a $P$. indica hyphal network.

\section{MATERIALS AND METHODS \\ Growth of the Organisms, A. brassicae Spore Infection, Co-cultivation of Arabidopsis and Fungi}

For the analysis of radial systemic signaling, a leaf of a 4 week-old Arabidopsis plant grown on garden soil in a square pot $(6 \times 6 \mathrm{~cm})$ 
under short day conditions was infected with $2 \mu \mathrm{l}$ of an Alternaria spore suspension $\left(1 \times 10^{6}\right.$ spores $\left./ \mathrm{ml}\right)$, as shown in Figure 1A. Preparation of the spore suspension has been described in Michal Johnson et al. (2014). The infected local leaf (no. 8, cf. Farmer et al., 2013) and the non-infected distal leaves (no. 11, according to Dengler, 2006, and no. 10) were harvested at the time points indicated and immediately frozen in liquid nitrogen for RNA extraction.

For the analysis of axial systemic signaling, Arabidopsis seedlings were grown vertically on $1 / 2 \mathrm{MS}$ medium in square plates for 2 weeks at long-day conditions $\left(80 \mu \mathrm{mol} \mathrm{m}{ }^{-2} \mathrm{~s}^{-1}\right.$; Figure 1B). The root area or leaf marked in Figure 1B were infected with $2 \mu \mathrm{l}$ of an Alternaria spore suspension $\left(1 \times 10^{6}\right.$ spores $/ \mathrm{ml}$ ) and both tissues were harvested separately at the time points indicated in the figures, immediately frozen in liquid nitrogen, and used for RNA extraction.

For interplant communication assays, $P$. indica was cultured as described previously (Verma and Varma, 1998; PeškanBerghöfer et al., 2004) in Petri dishes on a modified Kaefer's medium (KM). The plates were kept at room conditions for 2 weeks. A plaque of $5 \mathrm{~mm}$ diameter of KM media with and without (control) $P$. indica mycelium was transferred to the middle of a new plate, as shown in Figure 3. Four seedlings (2 week old, grown on $1 / 2 \mathrm{MS}$ medium) were positioned on each plate as shown in Figure 3, so that the root tips were in contact with the fungal (or control) plaque. The plates were kept for 2 days in continuous light of $65 \mu \mathrm{mol} \mathrm{m}{ }^{-2} \mathrm{~s}^{-1}$, before the onset of experimentation.

To inhibit the information flow from the leaves of the three seedlings infected with $A$. brassicae spores to the leaves of the unaffected neighboring seedling (cf. Figure 3, seedlings 5 and 6), three experiments were performed: (a) Roots of the infected and non-infected seedlings were separated by a cellophane membrane which prevents physical contact. (b) Mycelium and agar between the infected and uninfected seedlings were cut with a razor blade every 2 nd day, starting at day 0 . (c) 10 ppm benomyl which kills the mycelium (Paul et al., 2001) was applied to the hyphae connecting the seedlings, at day $0,2,5$, and 7. For some experiments shown in Figure 4, P. indica was replaced by the fungi Absidia glauca or Mucor mucedo (obtained from Institute of General Microbiology and Microbe Genetics, Jena).

For the data shown in Table 1, 4 seedlings (2 week-old, grown on MS medium with $0.3 \%(\mathrm{w} / \mathrm{v})$ gelrite) were transferred to PNM plates (Michal Johnson et al., 2014) with $0.3 \%$ (w/v) gelrite and $P$. indica (or a control plate without the fungus). The fungus was pre-grown on the plate for 7 days. Two of the seedlings (in alternate order) were infected with $A$. brassicae spores, and in the control plates, two were mock-treated with water. After 12 days of co-culture, the intact seedlings with their roots were removed from the plates, and those not treated with $A$. brassicae were used for RNA and hormone measurements.

All Arabidopsis mutants used in this study have been described: npr1 (Cao et al., 1997), jar1 (Staswick et al., 1992), myb72 (van der Ent et al., 2008), and rbohD knockout (Torres et al., 2002; gift from Prof. Jonathan DG Jones, Warwick, UK). The ABA mutants abi5-1 and aba2-1 were a gift from Prof. A. Gierl (Weihnstephan, Germany).

\section{RNA Analysis}

RNA was isolated from shoots and roots with an RNA isolation kit (RNeasy, Qiagen, Hilden, Germany). Reverse transcription of $1 \mu \mathrm{g}$ of total RNA was performed with oligo dT Primer and the Omniscript RT Kit (Qiagen, Hilden, Germany). Real-time quantitative reverse transcription-PCR (RT-PCR) was conducted with the following primer pairs:

NRT2.5 (At1G12940, CAGCTGATCATGCCCATCGTGTTC, GCGATGCATAAATCTGGAGAGAGGG), RRTF1 (At4g34410,

ACAGTGATAAGCGCGGGAAT, TCCACAAAGGGGAAG TTGAG), JAM1 (At2g46510, CTCCTCGGCCACGATGTCTCT CCGC, CATAATCCGCCAAAATCTCTTCCATTCCTTC), RD29A (At5G52310, GGTTGAAGAAGATGATGATG, GGAAG ACACGACAGGAAA), RAB18 (At5g66400, ATTCCCTTCT TCCTCCTC, TGAAGGCTTTGGAACTGG), housekeeping gene GAPDH (At3g04120, GAGCTGACTACGTTGTTGAG, GGA GACAATGTCAAGGTCGG).

The primer pairs used for PDF1.2, VSP2, and JAR1 were described in Scholz et al. (2014). Quantification of $A$. brassicae in infected and non-infected plant tissue (Figure 3C) was performed with the AbreATr1 gene marker (Guillemette et al., 2004, ACCCGCATTCCTCGCCAAA, AAGTCAAGGATTGTGTCGAGCTT) as described in Michal Johnson et al. (2014).

RT-PCR was performed using the Bio-Rad CFX connect realtime system and Bio-Rad CFX manager version 3.1 (Bio-Rad, Munich, Germany). For the amplification of the PCR products, Eva green (Bio-Rad) and Dream Taq DNA polymerase were used in a final volume of $20 \mu \mathrm{l}$. The CFX real-time PCR was programmed to $95^{\circ} \mathrm{C} 2 \mathrm{~min}, 39 \times\left(95^{\circ} \mathrm{C} 30 \mathrm{~s}, 60^{\circ} \mathrm{C} 40 \mathrm{~s}, 72^{\circ} \mathrm{C}\right.$ $45 \mathrm{~s}), 72^{\circ} \mathrm{C} 8 \mathrm{~min}$ followed by a melting curve program (55$95^{\circ} \mathrm{C}$ in increasing steps of $0.5^{\circ} \mathrm{C}$ ). Annealing temperature was calculated for each primer pair. All reactions were repeated three times. The mRNA levels for each cDNA probe were normalized with respect to the GAPDH mRNA levels.

\section{Phytohormone Measurement}

Leaf and root material was frozen in liquid nitrogen and kept at $-80^{\circ} \mathrm{C}$ until use. Thirty to One hundred and thirty milligrams of leaf or root material was ground with mortar and pestle, and extracted with $1.2 \mathrm{ml}$ of methanol containing $24 \mathrm{ng}$ of $9,10-$

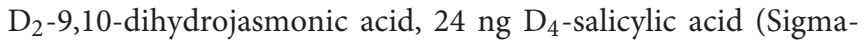
Aldrich), 24 ng $\mathrm{D}_{6}$-abscisic acid (Santa Cruz Biotechnology, Santa Cruz, U.S.A.), and 4.8 ng of JA- ${ }^{13} \mathrm{C}_{6}$-Ile conjugate as internal standards. $\mathrm{JA}^{-13} \mathrm{C}_{6}$-Ile conjugate was synthesized as described by Kramell et al. (1988) using ${ }^{13} \mathrm{C}_{6}$-Ile (Sigma-Aldrich). The homogenate was mixed for $30 \mathrm{~min}$ and centrifuged at 14,000 rpm for $20 \mathrm{~min}$ at $4^{\circ} \mathrm{C}$. The supernatant was collected. The homogenate was re-extracted with $500 \mu \mathrm{l}$ methanol, mixed well, centrifuged and supernatants were pooled. The combined extracts were evaporated in a speed-vac at $30^{\circ} \mathrm{C}$ and re-dissolved in $250 \mu \mathrm{l}$ methanol. Chromatography was performed on an Agilent 1200 HPLC system (Agilent Technologies). Separation was achieved on a Zorbax Eclipse XDB-C18 column (50 $\times 4.6 \mathrm{~mm}, 1.8 \mu \mathrm{m}$, Agilent). Formic acid (0.05\%) in water and acetonitrile were employed as mobile phases $\mathrm{A}$ and $\mathrm{B}$, 
A
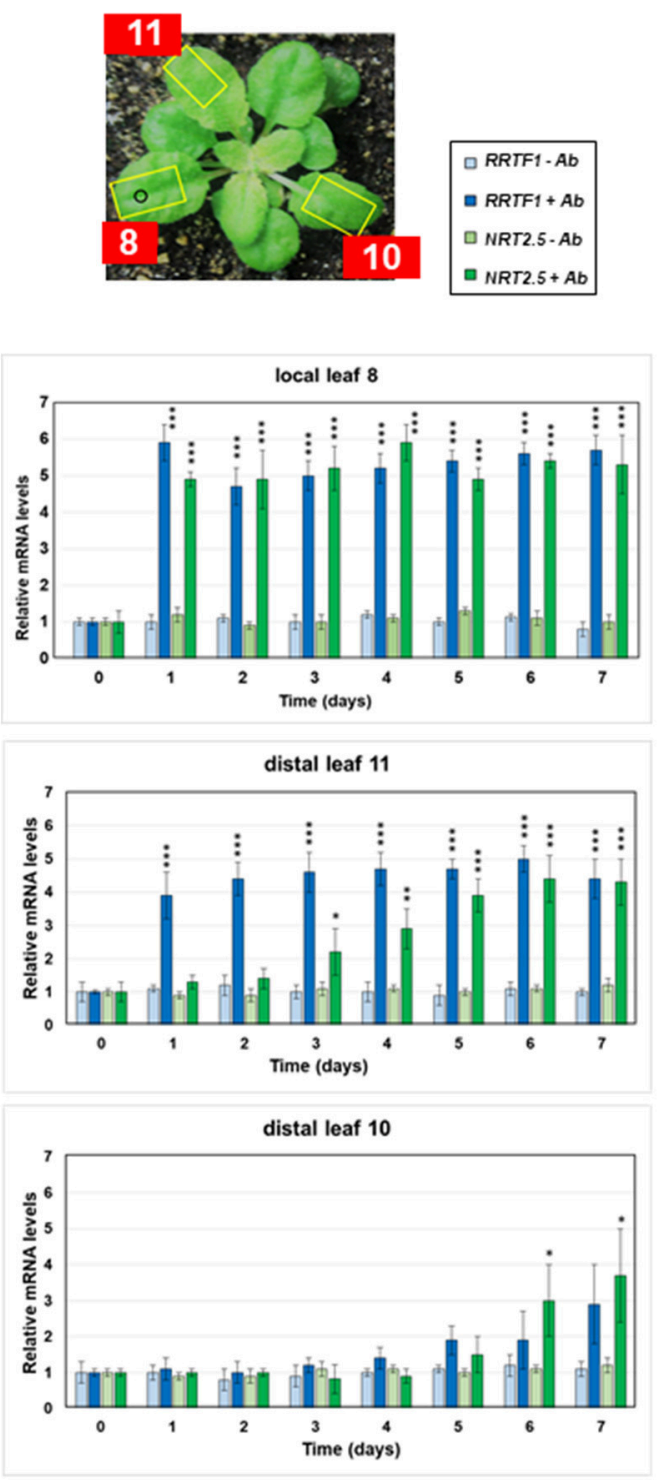

B
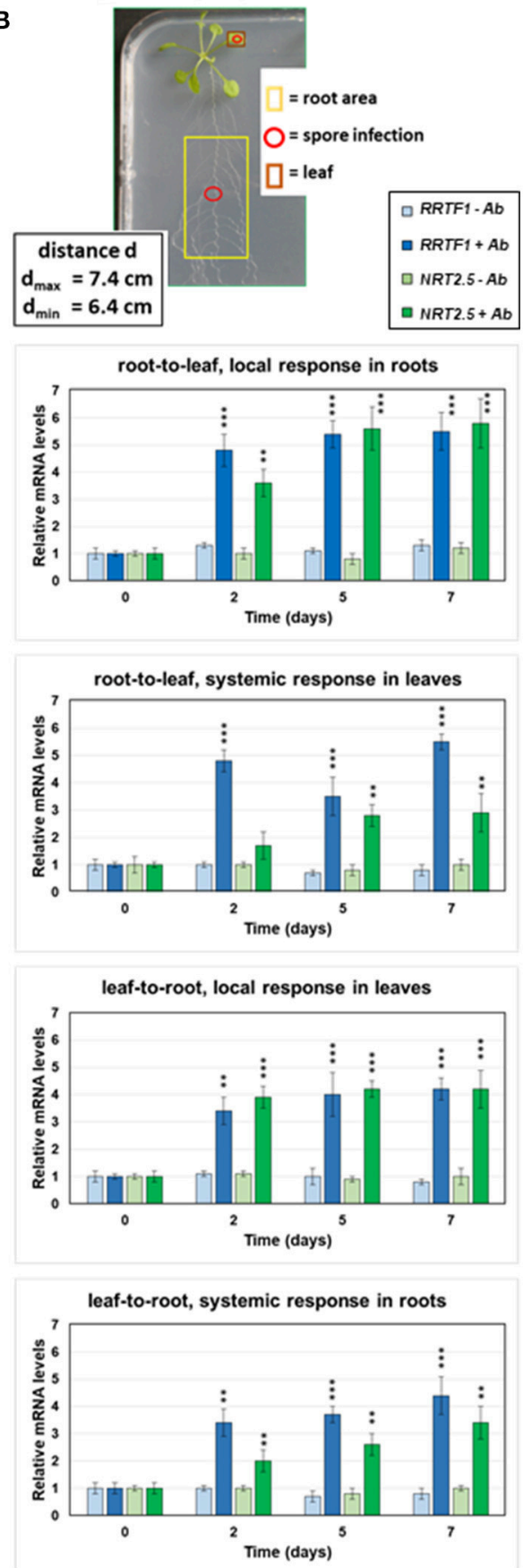

FIGURE 1 | Local and systemic induction of RRTF1 (blue bars) and NRT2.5 (green bars) mRNA levels by A. brassicae spore infection. (A) The picture shows the experimental set-up. The leaf numbers of 4-week-old seedlings, the $A$. brassicae infection area (0) and the sections used for RNA extraction (yellow squares) are shown. RRTF1 and NRT2.5 mRNA levels in the local infected leaf no. 8 and the distal leaves no. 11 and 10. At day 0, infection was performed with an A. brassicae spore suspension and the mRNA accumulation was followed in infected (darker bars) and mock (water)-treated (lighter bars) seedlings over a period of 7 days.

(B) The picture shows 2-week-old Arabidopsis seedlings grown in square Petri dishes for the measurements of RRTF1 and NRT2.5 mRNA levels in local and systemic tissues. The spore infection occurred either at the leaf or at the root (red o). The local and systemic leaf areas harvested for RNA isolation are indicated (red and yellow squares). The graphs show RRTF1 (blue bars) and NRT2.5 (green bars) mRNA levels in local and systemic tissues 0, 2, 5, and 7 days after application of an A. brassicae spore suspension (darker bars), lighter bars show water controls. All RNA data are based on 6 independent experiments with 10 seedlings for each treatment. The mRNA levels for the 4 datasets at day 0 were set as 1.0 and all other values were expressed relative to them ( \pm SEs). Asterisks indicate significant differences of the values for Alternaria-treated tissue compared to the corresponding water control at the same time point, as determined by Student's $t$-test ${ }^{*} P \leq 0.1$; $\left.{ }^{* *} P \leq 0.01 ;{ }^{* \star *} P \leq 0.001\right) .{ }^{* \star *}>$, all higher values have $P \leq 0.001$ compared to mock-treated controls. 
TABLE 1 | The experimental set-up is shown in Figures S1: 4 Arabidopsis seedlings were either transferred to plates without $P$. indica or to plates with a 1 week-old P. indica fungal lawn for 12 days.

\begin{tabular}{|c|c|c|c|c|}
\hline \multicolumn{5}{|l|}{ A } \\
\hline $\begin{array}{l}\text { Parameter measured } \\
\text { in roots of } \\
\text { A. brassicae-infected } \\
\text { seedlings }\end{array}$ & $\begin{array}{l}\text { No } P \text {. indica lawn } \\
\text { No } A \text {. brassicae } \\
\text { infection }\end{array}$ & $\begin{array}{l}\text { No } P \text {. indica lawn } \\
\text { A. brassicae } \\
\text { infection }\end{array}$ & $\begin{array}{l}\text { P. indica lawn } \\
\text { No } \\
\text { A. brassicae } \\
\text { infection }\end{array}$ & $\begin{array}{l}\text { P. indica lawn } \\
\text { A. brassicae } \\
\text { infection }\end{array}$ \\
\hline JA [ng/g dry weight] & $1510 \pm 127$ & $12610 \pm 333^{\star \star \star}$ & $1480 \pm 230$ & $10010 \pm 240^{\star \star \star}$ \\
\hline JA-lle [ng/g dry weight] & $5.1 \pm 1.2$ & $19.2 \pm 3.4^{\star \star \star}$ & $3.3 \pm 0.7$ & $4.7 \pm 2.5$ \\
\hline SA [ng/g dry weight] & $1216 \pm 144$ & $455 \pm 51^{\star \star}$ & $3420 \pm 341^{\star \star \star}$ & $2105 \pm 167^{\star \star \star}$ \\
\hline ABA [ng/g dry weight] & $2.2 \pm 0.4$ & $3.5 \pm 0.9$ & $2.1 \pm 0.3$ & $3.5 \pm 1.3^{\star \star \star}$ \\
\hline \multicolumn{5}{|l|}{ B } \\
\hline $\begin{array}{l}\text { Parameter measured } \\
\text { in roots of seedlings } \\
\text { not treated with } \\
\text { A. brassicae }\end{array}$ & $\begin{array}{l}\text { No } P \text {. indica } \\
\text { lawn } \\
\text { No } A \text {. brassicae } \\
\text { infection of } \\
\text { neighboring } \\
\text { seedlings }\end{array}$ & $\begin{array}{l}\text { No } P \text {. indica lawn } \\
\text { A. brassicae } \\
\text { infection of } \\
\text { neighboring } \\
\text { seedlings }\end{array}$ & $\begin{array}{l}P \text {. indica lawn } \\
\text { No } A \text {. brassicae } \\
\text { infection of } \\
\text { neighboring } \\
\text { seedlings }\end{array}$ & $\begin{array}{l}\text { P. indica lawn } \\
\text { A. brassicae } \\
\text { infection of } \\
\text { neighboring } \\
\text { seedlings }\end{array}$ \\
\hline JA [ng/g dry weight] & $1510 \pm 127$ & $1980 \pm 109$ & $1480 \pm 230$ & $4410 \pm 640^{\star \star \star}$ \\
\hline JA-lle [ng/g dry weight] & $5.1 \pm 1.2$ & $11.6 \pm 3.4$ & $3.3 \pm 0.7$ & $15.7 \pm 5.4$ \\
\hline $\begin{array}{l}\text { cis-OPDA [ng/g dry } \\
\text { weight] }\end{array}$ & $805 \pm 99$ & $870 \pm 127$ & $561 \pm 56$ & $1227 \pm 234^{\star \star \star}$ \\
\hline SA [ng/g dry weight] & $1216 \pm 144$ & $1010 \pm 121$ & $3420 \pm 341^{\star \star \star}$ & $2105 \pm 167^{\star \star}$ \\
\hline ABA [ng/g dry weight] & $2.2 \pm 0.4$ & $4.5 \pm 0.6$ & $2.1 \pm 0.3$ & $19.5 \pm 4.6^{\star \star \star}$ \\
\hline NRT2.5 mRNA level & $1.0 \pm 0.3$ & $1.1 \pm 0.4$ & $1.6 \pm 0.3$ & $3.5 \pm 0.6^{\star \star \star}$ \\
\hline RRTF1 mRNA level & $1.0 \pm 0.4$ & $1.5 \pm 0.4$ & $1.3 \pm 01$ & $3.7 \pm 0.9^{\star \star \star}$ \\
\hline PDF1 mRNA level & $1.0 \pm 0.2$ & $1.4 \pm 0.5$ & $0.8 \pm 0.4$ & $2.2 \pm 0.3^{\star \star}$ \\
\hline VSP2 mRNA level & $1.0 \pm 0.2$ & $1.3 \pm 0.2$ & $1.0 \pm 0.2$ & $1.9 \pm 0.4^{\star \star}$ \\
\hline
\end{tabular}

Parameter measured in roots of abi1-5 seedlings not treated with $\boldsymbol{A}$. brassicae (Finkelstein and Lynch, 2000)

\begin{tabular}{lllll}
\hline RD29A mRNA level & $1.0 \pm 0.3$ & $1.4 \pm 0.3$ & $1.1 \pm 0.1$ & $0.7 \pm 0.3$ \\
RAB18 mRNA level & $1.0 \pm 0.1$ & $1.2 \pm 0.3$ & $1.3 \pm 0.4$ & $1.0 \pm 0.3$ \\
JAM1 mRNA level & $1.0 \pm 0.3$ & $1.1 \pm 0.1$ & $1.2 \pm 0.3$ & $1.1 \pm 0.1$
\end{tabular}

D

Parameter measured in roots of aba2-1 seedlings not treated with $A$. brassicae

\begin{tabular}{|c|c|c|c|c|}
\hline RD29A mRNA level & $1.0 \pm 0.0$ & $1.5 \pm 0.1$ & $13 \pm 0.1$ & $1.5 \pm 0.2$ \\
\hline RAB18 mRNA level & $1.0 \pm 0.2$ & $1.3 \pm 0.1$ & $1.3 \pm 0.2$ & $1.7 \pm 0.4$ \\
\hline JAM1 mRNA level & $1.0 \pm 0.3$ & $1.2 \pm 0.2$ & $1.2 \pm 0.2$ & $1.4 \pm 04$ \\
\hline
\end{tabular}

Two of the four 4 seedlings were inoculated with an A. brassicae spore suspension applied to the leaves, or they were mock-treated with water, the other two seedlings remained untreated. After 12 days the treated (A) and untreated (B) seedlings were removed from the gelrite and the phytohormone (and mRNA levels) determined in their roots. (C,D), same as (B), except as the non-A-brassicae treated seedlings was abi5-1 or aba2-1. Based on 5 (hormone data) and 6 (RNA data) independent experiments, bars represent SEs. Asterisks indicate significant differences of the values compared to the corresponding control (no P. indica, no A. brassicae, column 1), as determined by Student's t-test ( ${ }^{*} P \leq 0.1$; ${ }^{* *} P \leq 0.01$; $\left.{ }^{\star \star *} P \leq 0.001\right)$. Light grew data are identical in $(\boldsymbol{A}, \boldsymbol{B})$. 
respectively. The elution profile was: $0-0.5 \mathrm{~min}, 5 \% \mathrm{~B} ; 0.5-$ 9.5 min, 5-42\% B; 9.5-9.51 min 42-100\% B; 9.51-12 min $100 \%$ $\mathrm{B}$, and $12.1-15 \mathrm{~min} 5 \% \mathrm{~B}$. The mobile phase flow rate was $1.1 \mathrm{ml} / \mathrm{min}$. The column temperature was maintained at $25^{\circ} \mathrm{C}$. An API5000 tandem mass spectrometer (Applied Biosystems) equipped with a Turbospray ion source was operated in negative ionization mode. The instrument parameters were optimized by infusion experiments with pure standards, where available. The ionspray voltage was maintained at $-4,500 \mathrm{eV}$. The turbo gas temperature was set at $700^{\circ} \mathrm{C}$. Nebulizing gas was set at $60 \mathrm{psi}$, curtain gas at $25 \mathrm{psi}$, heating gas at $60 \mathrm{psi}$, and collision gas at $7 \mathrm{psi}$. Multiple reaction monitoring (MRM) was used to monitor analyte parent ion $\rightarrow$ product ion: $\mathrm{m} / \mathrm{z} 136.9 \rightarrow 93.0$ [collision energy (CE) $-22 \mathrm{~V}$; declustering potential $(\mathrm{DP})-35 \mathrm{~V}]$ for SA; m/z $140.9 \rightarrow 97.0(\mathrm{CE}-22 \mathrm{~V}$; $\mathrm{DP}-35 \mathrm{~V})$ for D4-SA; m/z 209.1 $\rightarrow 59.0(\mathrm{CE}-24 \mathrm{~V}$; DP $-35 \mathrm{~V})$ for $\mathrm{JA} ; \mathrm{m} / \mathrm{z} 213.1 \rightarrow 56.0(\mathrm{CE}-24 \mathrm{~V} ; \mathrm{DP}-35 \mathrm{~V})$ for 9,10-D2-9,10-dihydrojasmonic acid; $\mathrm{m} / \mathrm{z} 263.0 \rightarrow 153.2$ $(\mathrm{CE}-22 \mathrm{~V} ; \mathrm{DP}-35 \mathrm{~V})$ for $\mathrm{ABA} ; \mathrm{m} / \mathrm{z} 269.0 \rightarrow 159.2(\mathrm{CE}$ $-22 \mathrm{~V} ; \mathrm{DP}-35 \mathrm{~V})$ for D6-ABA; m/z $322.2 \rightarrow 130.1(\mathrm{CE}$ $-30 \mathrm{~V} ; \mathrm{DP}-50 \mathrm{~V})$ for JA-Ile conjugate; $\mathrm{m} / \mathrm{z} 328.2 \rightarrow 136.1$ $(\mathrm{CE}-30 \mathrm{~V} ; \mathrm{DP}-50 \mathrm{~V})$ for $\mathrm{JA}^{-13} \mathrm{C}_{6}$-Ile conjugate. Both $\mathrm{Q} 1$ and Q3 quadrupoles were maintained at unit resolution. Analyst 1.5 software (Applied Biosystems) was used for data acquisition and processing. Linearity in ionization efficiencies were verified by analyzing dilution series of standard mixtures. Phytohormones were quantified relative to the signal of their corresponding internal standard. For quantification of 12-oxophytodienoic acid, cis-OPDA, 9,10-D2-9,10-dihydro-JA was used as the internal standard applying an experimentally determined response factor of 1 .

\section{Confocal Microscopy}

Twelve days after infection of $A$. thaliana with GFP-labeled $P$. indica (gift from Prof. P. Schäfer, Warwick, UK) root colonization was imaged using a LSM 880 (Zeiss Microscopy $\mathrm{GmbH}$, Jena, Germany) with the $488 \mathrm{~nm}$ laser line of an argon multiline laser (Figure 2B). Images were taken with a 40x objective (Plan-Apochromat 40x/0.8). A maximum intensity projection was performed from a z-stack of 26 plains each $0.5 \mu \mathrm{m}$. Digital images were processed by ZEN software.

\section{ROS Measurements}

Quantitative ROS measurements from leaves were performed with the Amplex Red hydrogen peroxide/peroxidase assay kit (Molecular Probes, Invitrogen, Carlsbad, CA, USA) according to the manufacturer's instructions (https://tools.thermofisher.com/ content/sfs/manuals/mp22188.pdf). Leaf sections of $0.5-1 \mathrm{~mm}$ width were incubated in the reaction mixture for $10 \mathrm{~min}$ in dark at room temperature. The fluorescence intensity was quantified with a fluorescence microplate reader (TECAN Infinite 200 plate reader; Crailsheim, Germany) with excitation at $540 \mathrm{~nm}$ and emission at $610 \mathrm{~nm} . \mathrm{H}_{2} \mathrm{O}_{2}$ was used to prepare the standard curve. The reaction mixture without the molecular probe or without the plant material served as control.

\section{RESULTS}

\section{Radial and Axial Systemic Induction of NRT2.5 and RRTF1 by Alternaria brassicae Infection}

Since interplant signal transfer requires systemic information flow within a plant, we looked for genes which responded systemically to various threats in preliminary experiments and decided for NRT2.5 and RRTF1 as read-out to assay information transfer for radially and axially traveling signals. The genes were chosen for study because they responded to various diseaseinducing fungal infections in preliminary studies, are not directly related to phytohormone responses, represent responses to systemic signals which are not directly related to each other, and are involved in the primary metabolism and defense strategies (cf. section Introduction).

Arabidopsis leaf no. 8 was infected with $2 \mu \mathrm{l}$ of an Alternaria spore suspension $\left(1 \times 10^{6}\right.$ spores $\left./ \mathrm{ml}\right)$ or mock-treated with water. The NRT2.5 and RRTF1 mRNA levels were measured in the infected leaf and in distal non-infected leaf no. 11, which is vascularly connected to the infected leaf (Figure 1A, Dengler, 2006). A strong increase in the mRNA levels relative to the mock-treated controls was detectable in the infected leaf 1 day after spore application and the mRNA levels remained high until the 7 th day. In distal leaf no. 11, a significant increase was detected between 1 (RRTF1) and 3 (NRT2.5) days after infection and the RRTF1 mRNA level responded much earlier than the NRT2.5 mRNA level (Figure 1A). Since only a low elevation in the NRT2.5 and RRTF1 mRNA levels was observed in the nonconnected distal leaf no. 10, and the response started much later (Dengler, 2006; Kiep et al., 2015), a volatile compound as signal transducer is unlikely (Figure 1A). Likewise, when the roots of seedlings were infected with $A$. brassicae spores (Figure 1B), the expression of the two genes increased within the first 2 days in the roots. An increased expression in the leaves was detected between the 2nd (RRTF1) and 5th (NRT2.5) day (Figure 1B). Again, the mRNA level for RRTF1 responded earlier than that for NRT2.5. The information also traveled from the leaf toward the root with a comparable induction observed in roots when the leaves were infected with A. brassicae spores (Figure 1B). This indicates that NRT2.5 and RRTF1 are systemically induced in non-infected leaves or roots by radially and axially migrating signals, and the axial information flow is bidirectional.

\section{Local and Systemic Induction of NRT2.5 Is JAR1-Dependent and Induction of RRTF1 Is RBOHD-Dependent}

A. brassicae infection induces JA, but not salicylic acid (SA) accumulation in the infected host tissue (Michal Johnson et al., 2014). To test whether RRTF1 and NRT2.5 regulation is linked to these hormones, we measured the induction of the RNA levels in the hormone mutants jar1 and npr1. JAR1 catalyzes the formation of the biologically active jasmonyl-isoleucine (JAIle) conjugate, and NPR1 is a receptor for SA (Wu et al., 2012). The mRNA levels were determined in infected local leaves (as shown in Figures 1A,B), the distal leaf no. 11 (as 


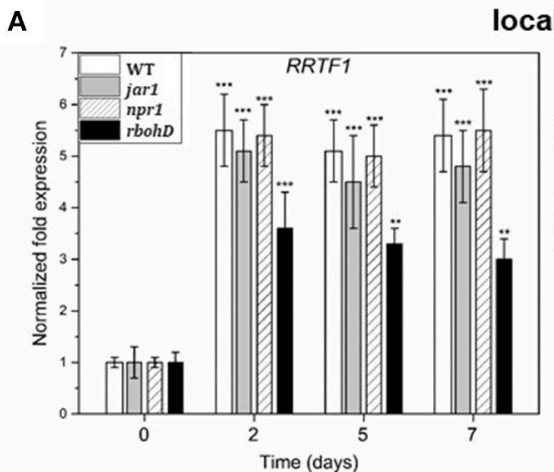

local leaf 8

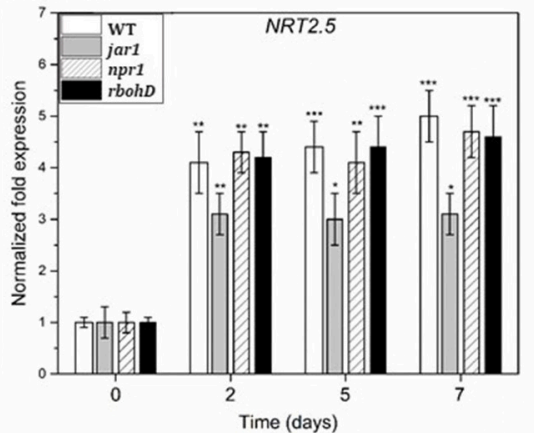

distal leaf 11
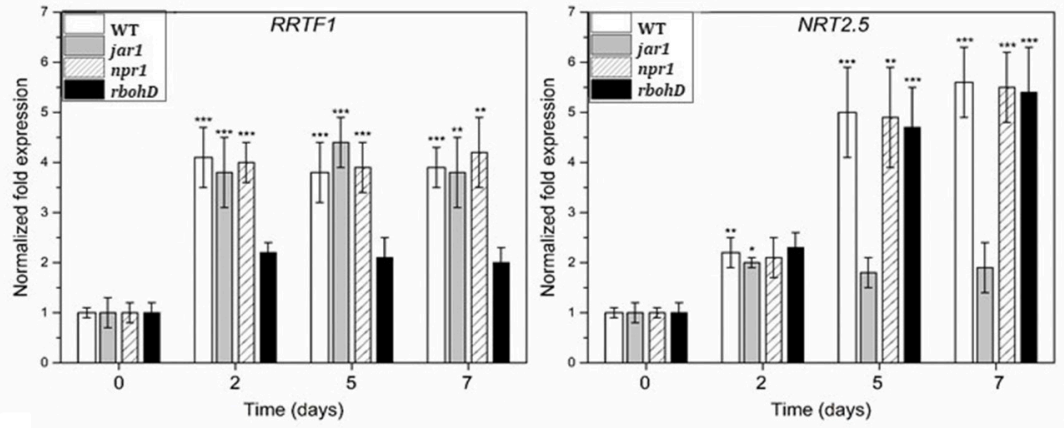

B

leaf-to-root, local response in leaves
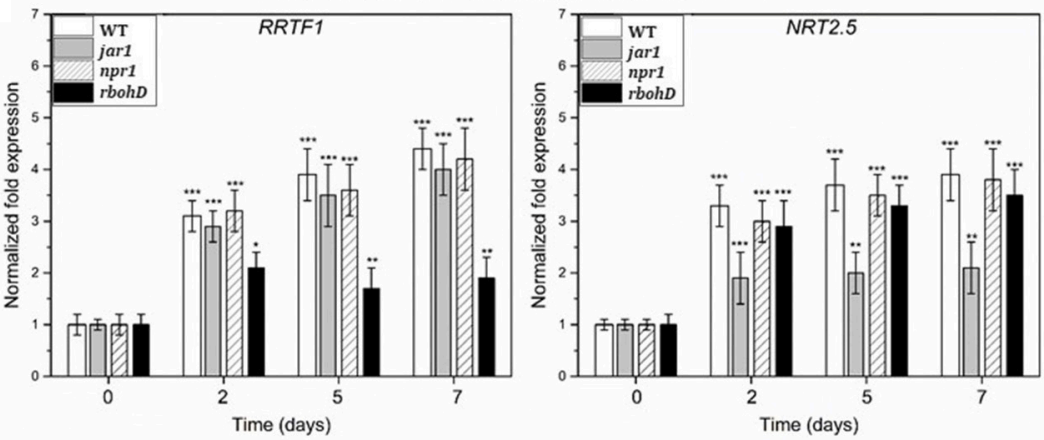

leaf-to-root, systemic response in roots
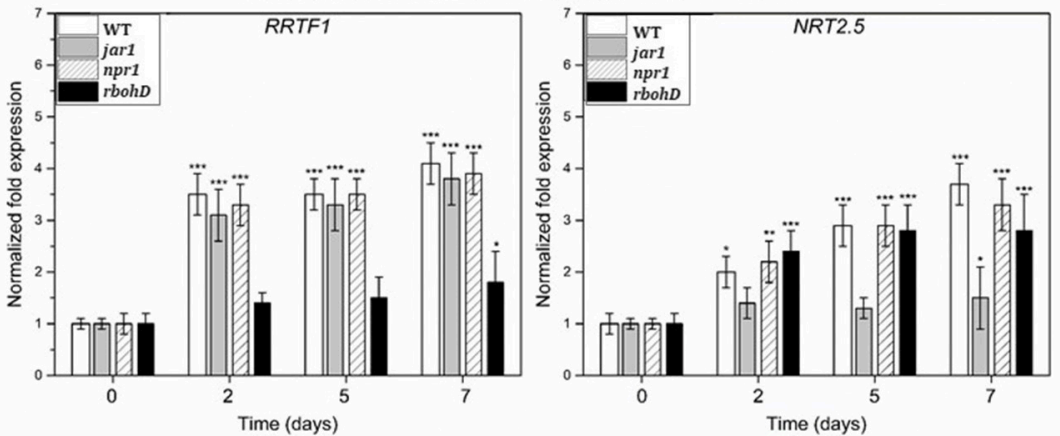

FIGURE 2 | (A) Induction of RRTF1 and NRT2.5 mRNA levels in the A. brassicae-infected leaf no. 8 and the systemic leaf no. 11 of WT, jar1, npr1, and rbohD plants. The treatment was the same as described in the legend to Figure 1A. (B) Induction of RRTF1 and NRT2.5 mRNA levels in the A. brassicae-infected leaves and the non-infected roots of WT, jar1, npr1, and rbohD seedlings on agar plates, as shown in the Figure 1B. The treatment was the same as described in the legend to Figures $1 \mathbf{A}, \mathbf{B}$. The mRNA levels at day 0 were set as 1.0 and all other values were expressed relative to them ( \pm SEs). Asterisks indicate significant differences of the values compared to the mock-treated controls (which are not shown, but comparable to the results shown for WT material in Figure 1), as determined by Student's $t$-test $\left({ }^{\star} P \leq 0.1 ;{ }^{* \star} P \leq 0.01 ;{ }^{* \star *} P \leq 0.001\right)$. 
shown in Figure 1A) and roots of seedlings with leaf infection (shown in Figure 1B). RRTF1 expression was comparable to the WT in jar1 and npr1 plants. NRT2.5 induction in local (leaf no. 8) and distal (leaf no. 11) tissue was inhibited in the jarl mutant, but not in the npr1 mutant in which part of the SA response was inhibited (cf. Herrera-Vásquez et al., 2015; Figure 2). Furthermore, RRTF1 expression has been shown to be induced by ROS (Khandelwal et al., 2008; Matsuo et al., 2015) and A. brassicae infection reported to stimulate ROS accumulation in local and systemic tissues, mainly via the $\mathrm{H}_{2} \mathrm{O}_{2}$-producing $\mathrm{RBOHD}$, a plasmamembrane-localized NADH oxidase preferentially activated in response to pathogen attacks (Michal Johnson et al., 2014; Matsuo et al., 2015 and ref. therein;). The stimulatory effect on RRTF1 expression in both local and systemic tissues was reduced in the rbohD mutant (Figure 2), while NRT2.5 expression was not affected. This suggests the involvement of ROS produced by RBOHD in the local and systemic RRTF1 response. Finally, MYB72, a transcription factor up-regulated by infection of non-pathogenic rhizobacteria that plays a crucial role in induced systemic resistance and rootto-shoot signaling (Segarra et al., 2012), was found to be not involved in the axial systemic information flow from the roots to the leaf leading to NRT2.5 and RRTF1 induction, since this information flow was not impaired in the myb72 mutant (data not shown, since they are not significantly different from the WT responses). Taken together, local and systemic induction of NRT2.5, but not RRTF1, is partially dependent on jasmonate signaling, whereas local and systemic $R R T F 1$ regulation is partially dependent on RBOHD.

\section{Piriformospora indica Involvement in Interplant Communication: Experimental Set-Up}

Figure 3A shows the experimental design used for interplant communication assays. Four Arabidopsis seedlings were grown in a Petri dish. In plate 1 , the four seedlings were not exposed to any fungus (sample 1), in plate 2, the leaves of three seedlings were infected with an A. brassicae spore suspension (sample 2), while the fourth seedling remained uninfected (sample 3). In the 3rd and 4th plate, the Arabidopsis seedlings were grown in the presence of a $P$. indica hyphal network. While seedlings in the 3rd plate received no additional treatment (sample 4), the leaves of three seedlings in the 4 th plate were infected with A. brassicae spores (sample 5). The 4 th seedling was not infected by the pathogen, but connected to the infected seedlings via a $P$. indica hyphal network (sample 6). $P$. indica forms a hyphal network that connects the roots of the 4 plants on the plate (Figure 3B). The majority of the hyphae associated with the seedlings can be detected around the primary, secondary and lateral roots. The percentage of hyphae that are visible inside root cells was low. Until the end of the experiment (12 days after infection), we could not detect dead plant cells caused by $P$. indica infection (cf. Figure 3B). A. brassicae spores germinated on the infected seedling but no pathogen DNA was detected by real-time PCR in the non-infected seedlings growing next to the infected seedlings (Figure 3C). Time course experiments demonstrated that significant amounts of pathogen DNA were first detected
$48 \mathrm{~h}$ after spore application in the infected seedlings. As expected, between the third and 12th day, the amount of pathogen DNA in the infected seedlings increased dramatically (Figure 3C).

\section{NRT2.5 and RRTF1 Respond to Signals From A. brassicae-Treated Neighboring Plants Through a $P$. indica Network}

Figure 4A demonstrates that NRT2.5 and RRTF1 expression is also induced by signals from neighboring plants. The mRNA abundance of these two genes increased in the leaves of noninfected seedlings when they were connected by a $P$. indica mycelial network to the infected seedlings (Figure 4A). No induction was detected when the $P$. indica hyphal connection was interrupted, either by the insertion of a cellophane membrane which cannot be penetrated by hyphae (Vahabi et al., 2015a,b), by cutting the hyphae with a razor blade (cut) or application of 10 ppm of benomyl to the P. inidca hyphae, which kills the mycelium (Paul et al., 2001; Figure 4B). Interestingly, $P$. indica could not be replaced by Absidia glauca or Mucor mucedo (Figure 4B), two fungi which associate with but do not colonize Arabidopsis roots. This suggests that a physical contact via the $P$. indica hyphal network is required for NRT2.5 and RRTF1 induction in neighboring non-stress exposed plants.

Furthermore, induction of NRT2.5 and RRTF1 mRNA was measured for the jarl and rbohD mutants. Using the same experimental design as shown in Figure 3, wild-type seedlings were replaced by either jarl or rbohD seedlings, in all possible combinations. Consistent with the results obtained for systemic signal propagation within the infected plant, we observed that if one of the partners was jarl or rbohD, there was no significant response of NRT2.5 (jar1) or RRTF1 (rbohD) in the leaves of the receiving plants connected via the $P$. indica hyphal connection to the infected plants (data not shown). It appears that the information cannot travel if one or both of the partners is a mutant, or occurs at a rate too low to measure.

\section{Volatiles Do Not Induce NRT2.5 and RRTF1 Expression in Uninfected Neighboring Plants}

To confirm that volatiles do not participate in the stimulation of NRT2.5 and RRTF1 in uninfected seedlings, a split Petri dish experiment was performed. Wild-type Arabidopsis seedlings were grown on one half of the Petri dish, while in the other half, we grew either an Arabidopsis plant alone, one colonized by $P$. indica, one exposed to A. brassicae, or one with both $P$. indica and A. brassicae. Furthermore, Arabidopsis seedlings were exposed to $P$. indica or $A$. brassicae hyphae or a combination of both fungi in the neighboring chamber. In none of these experiments, did we observe elevated NRT2.5 and RRTF1 mRNA levels in Arabidopsis seedlings compared to the control (Figure 5). Stimulation of both mRNA levels were only measured in the experimental set-up with a $P$. indica hyphal connection between the two seedlings (marked in black in Figure 5). This supports the idea that a physical contact is required for the information transfer to the neighboring plant for the induction of NRT2.5 and RRTF1. 


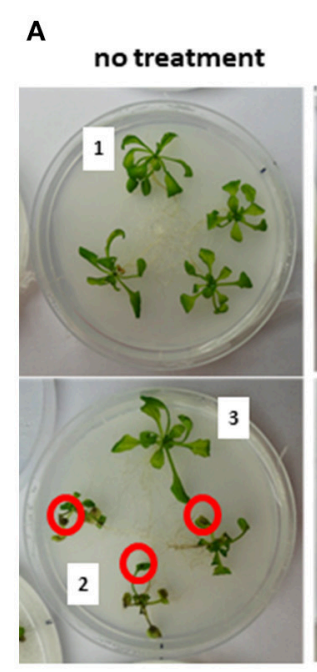

+ A. brassicae (O)
$+P$. indica $(\swarrow)$
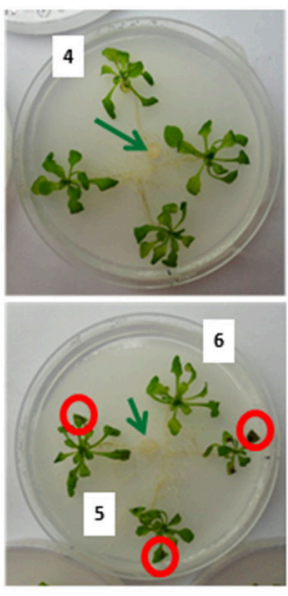

$+P$. indica \&

+ A. brassicae
C
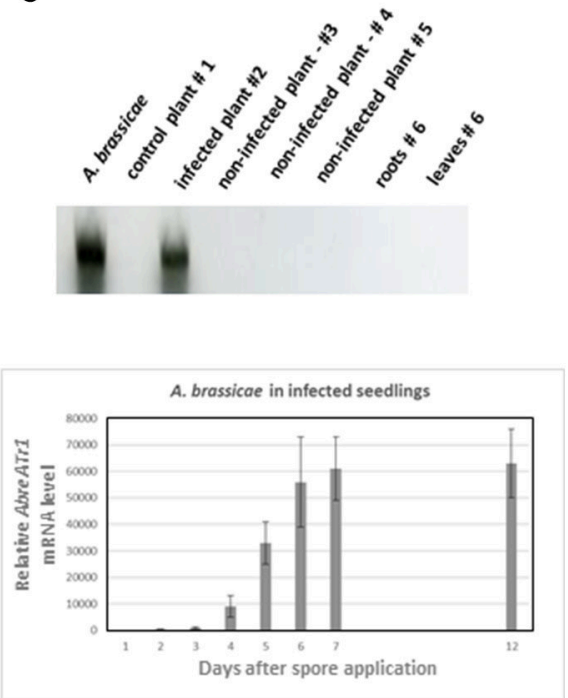

B
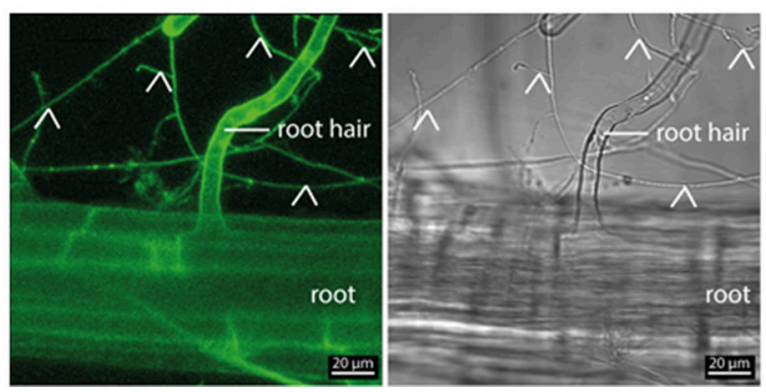

FIGURE 3 | (A) Experimental set-up for interplant communication. Four 2-week-old Arabidopsis seedlings were positioned in a fresh Petri dish. The roots were not connected (left two Petri dishes) or connected (right two Petri dishes) to each other via P. indica hyphae; $P$. indica was inoculated 1 week before transfer of the seedlings to the plates (cf. section Methods and Materials). The leaves of six seedlings were inoculated with an $A$. brassicae spore suspension (circled in red). The leaves of the seedlings 1-6 were harvested $0,2,5,7$, and 12 days after infection for RNA extraction and qPCR analyses. (1, no treatment; 2, A. brassicae infected material; 3, seedlings grown next to $A$. brassicae-infected seedlings, 4-6, as 1-3, except that seedlings were connected by a $P$. indica hyphal network) (B) Confocal image of an Arabidopsis root grown on the $P$. indica hyphal lawn for 12 days (end of experiment). The signal detected with the GFP channel is shown on the left and a bright field image on the right; root hairs are indicated by the label and fungal hyphae by arrow heads. (C) Quantification of $A$. brassicae AbreATr1 mRNA by qPCR. The gel shows amplified cDNA fragments from mRNAs of the seedlings \#1-6 after 12 days of co-cultivation which are shown in panel A. A. brassicae: PCR product from RNA of an A. brassicae culture was used as positive control. The graph shows relative AbreATr 1 mRNA levels of the infected seedlings \#2 between 0 and 12 days after spore application. Based on 6 independent experiments with 10 seedlings each. Error bars are SEs.

\section{Phytohormone and}

\section{Phytohormone-Responsive Genes in Infected and Non-infected Neighboring Plants}

To further elucidate how information about infection is transferred to non-infected neighboring plants, we checked defense-related phytohormone levels. A. brassicae is known to stimulate JA but not SA accumulation, whereas $P$. indica stimulates SA, but not JA accumulation (Michal Johnson et al., 2014). Consistent with these observations, plants which were only infected by $A$. brassicae (seedling 2 in Figure 3A) had higher JA levels compared to the untreated control (seedling 1 in Figure 3A), while the SA level was slightly reduced (Figure 6A). In seedlings which were only exposed to $P$. indica (seedling
4 in Figure 3A), the SA level was high, while the JA, JA-Ile and cis-OPDA levels were comparable to those in seedlings not exposed to any fungus (Figure 6A). Interestingly, $A$. brassicae infection also stimulated the JA, JA-Ile, and cis-OPDA levels in non-infected seedlings growing next to infected seedlings, if they were not connected via a $P$. indica hyphal network (seedling 3 in Figures 3A, 6A). This is particularly striking for cis-OPDA, the precursor for JA, and JA-Ile, the active form of JA (Figure 6A). Apparently, the information is either transferred through the gas phase or by chemical mediators diffusing through the agar to the non-infected neighboring plants. The JA, JA-Ile, and cis-OPDA levels were also upregulated in Arabidopsis plants that were growing separately from A. brassicae-infected plants in split Petri dishes (Figure 6B). The phytohormone levels in seedlings grown in split Petri dishes and those grown in the 


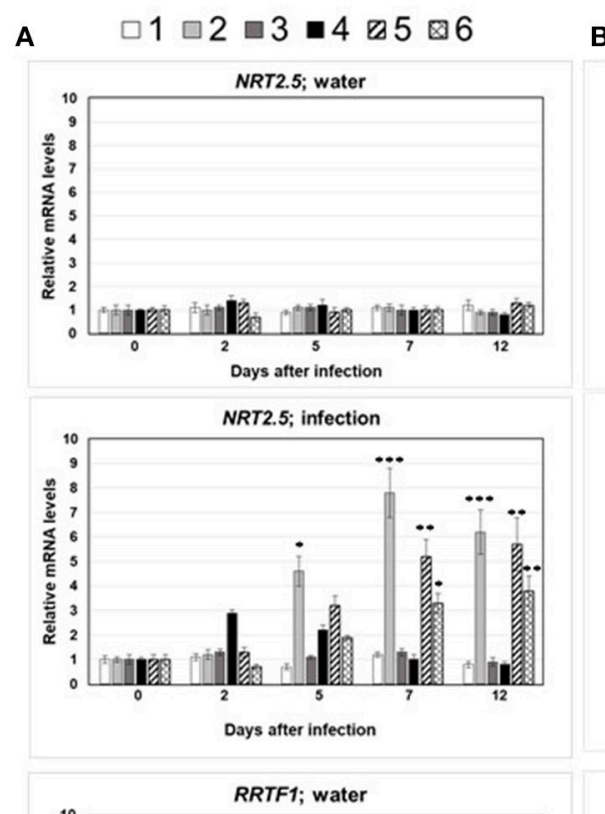

B
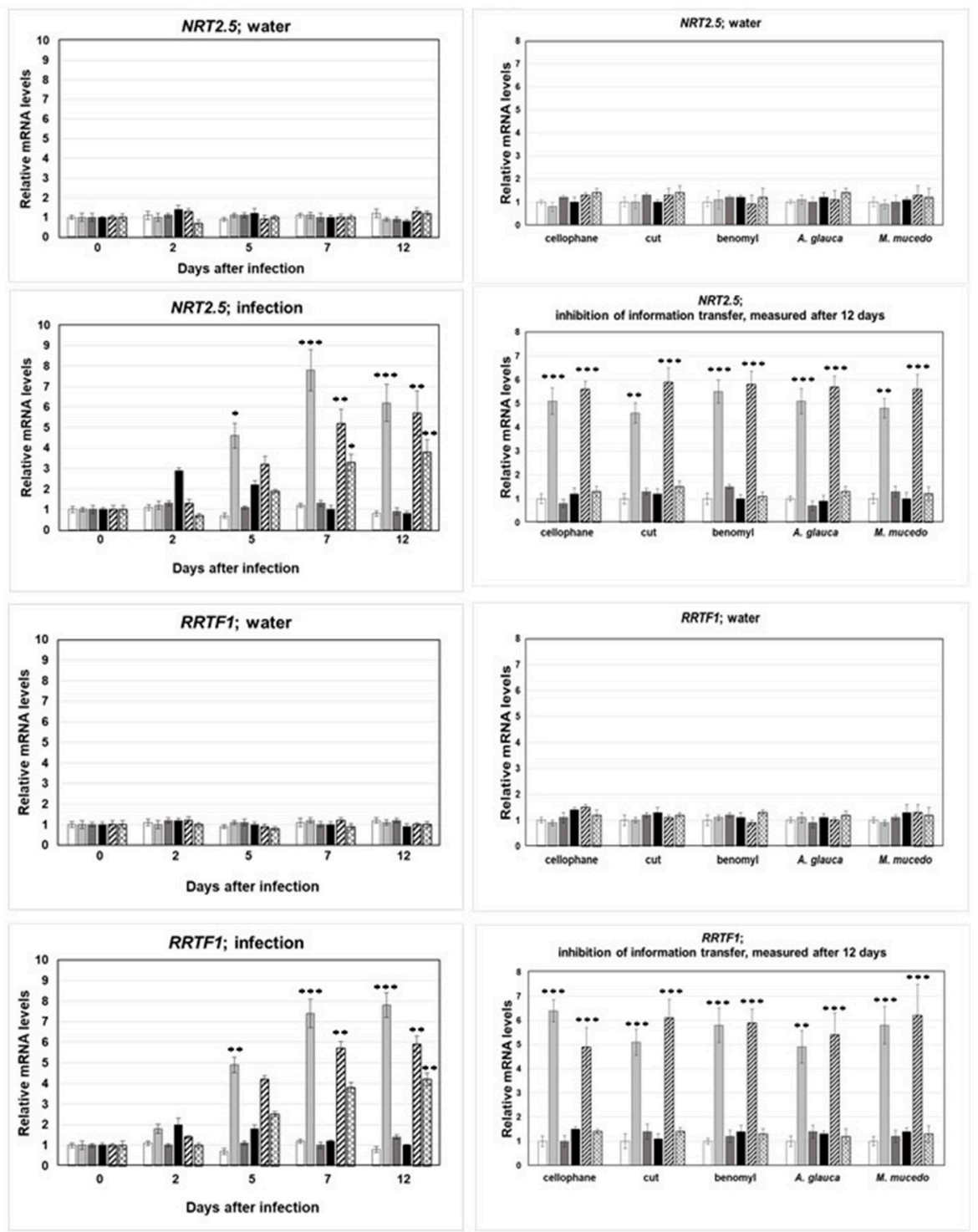

FIGURE 4 | (A) NRT2.5 and RRTF1 mRNA levels in infected and systemic leaves following A. brassicae spore application at day 0. The seedlings were either mock-treated (water) or inoculated with $A$. brassicae spores (infection). The numbers 1-6 refer to the seedlings shown in Figure 3A: 1, no treatment; 2, $A$. brassicae infected material; 3, seedlings grown next to A. brassicae-infected seedlings, 4-6, as 1-3, except that seedlings were connected by a $P$. indica hyphal network. The mRNA levels at the time point of infection $(t=0)$ was set as 1.0 and all other values are expressed relative to them. (B) NRT2.5 and RRTF1 mRNA levels in leaves of neighboring non-infected plants requires $P$. indica hyphal connection. Same experiment as in (A), but the connection between the roots via $P$. indica hyphae were interrupted by the insertion of a cellophane membrane (cellophane), or the hyphal connections were cut with a razor blade every 2 nd day (cut), or $P$. indica were treated with benomyl at day $0,2,5$, and 7 (benomyl). A. glauca, M. mucedo; $P$. indica was replaced by these fungi. All measurements were performed 12 dai and are based on 6 independent experiments with 10 plants each. Asterisks indicate significant differences of the values for $A$. brassicae-treated tissue compared to the corresponding water control at the same time point, as determined by Student's $t$-test $\left({ }^{\star} P \leq 0.1 ;{ }^{\star \star} P \leq 0.01 ;{ }^{\star \star \star} P \leq 0.001\right)$. The data for the water control did not change significantly within the 12 days and were below $1.5 \pm 0.4$.

"normal" Petri dishes were comparable and not significantly different from each other (Figures 6A,B). This supports the idea of information transfer through the air. A. brassicae-induced JA accumulation was completely prevented and JA-Ile and cis-OPDA strongly reduced in infected (seedling 5 in Figure 3A) and neighboring (seedling 6 in Figure $3 \mathbf{A}$ ) seedlings that were exposed to $P$. indica. This is most likely caused by the stimulating effect of $P$. indica on SA accumulation: its level is high in all seedlings which were growing on plates with $P$. indica but strongly inhibited when A. brassicae was present in the plate, either alone or in combination with $P$. indica (Figure 6). Thus, P. indica represses A. brassicae-induced JA, JA-Ile and cis-OPDA 

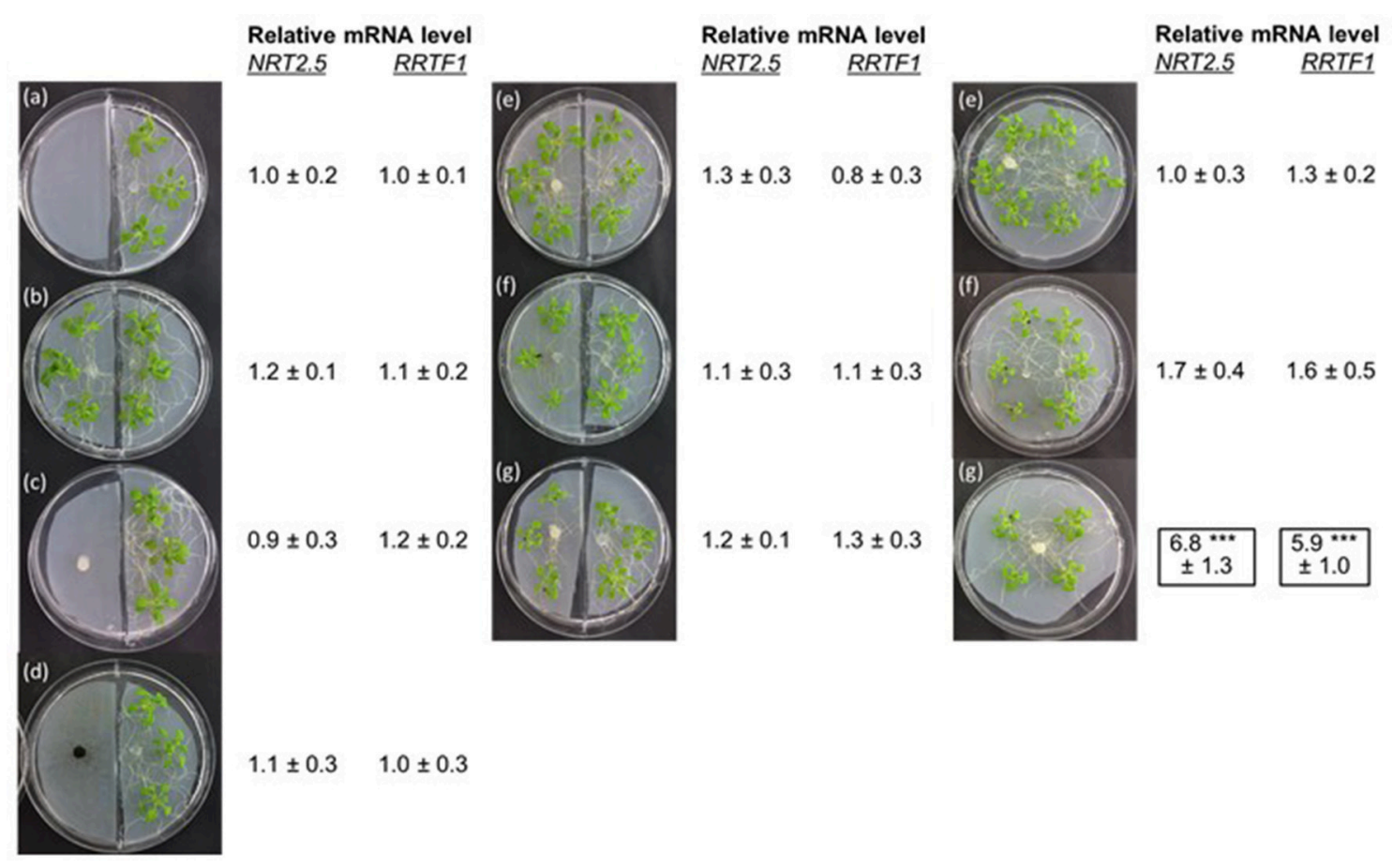

FIGURE 5 | NRT2.5 and RRTF1 mRNA levels in Arabidopsis seedlings grown in the right chamber of a split Petri dish. The other chamber contained either PNM medium alone (a), or PNM medium with Arabidopsis seedlings (b), P. indica (c), or A. brassicae (d) hyphae or Arabidopsis seedlings co-cultivated with the fungi, as described in the legends to the Figures 2, 3 (e, P. indica alone, f, Arabidopsis infected with A. brassicae spores, g, Arabidopsis seedlings exposed to both fungi). The organisms grown in the three Petri dishes on the right site were not separated from each other. RNA extraction was performed 12 days. The mRNA levels of Arabidopsis seedlings with only PNM medium in the neighboring chamber was set as 1.0 and all other values are expressed relative to them. Based on 6 independent experiments with 10 seedlings for each treatment.

accumulation and $A$. brassicae represses $P$. indica-induced SA accumulation in both infected and non-infected plants. This is not surprising considering the crosstalk between the two hormones (cf. Caarls et al., 2015). Interestingly, in seedlings not infected by $A$. brassicae, but connected to infected seedlings via a $P$. indica hyphal network (seedling 6 in Figure 3A), the ABA level was $>3$-fold higher. The ABA level was not stimulated by $P$. indica or A. brassicae alone, or the combination of both fungi, or in non-infected seedlings without $P$. indica fungal connection to infected seedlings (Figure 6). Moreover, the ABA level was not elevated in non-infected seedlings grown in the presence of $P$. indica, when A. brassicae infected seedlings were growing next to them in split Petri dishes, although they had elevated JA, JA-Ile, and cis-OPDA levels (Figure 6B). Thus, stimulation of ABA accumulation in non-infected seedlings growing next to $A$. brassicae-infected seedlings requires the $P$. indica hyphal bridge, and is apparently not caused by a JA-ABA crosstalk during the interactions (discussed in various contexts in RobertSeilaniantz et al., 2011; Kazan and Manners, 2012; Yang et al., 2013; de Ollas and Dodd, 2016; Di et al., 2016; Verma et al., 2016).

The different phytohormone levels are reflected in the expression pattern of phytohormone-responsive genes. Whenever JA, JA-Ile, or cis-OPDA was high, we observed elevated mRNA levels for the marker genes PDF1.2, VSP2, and JAR1, and elevated SA levels stimulated $P R-1$ mRNA accumulation. Finally, the RD29A, RAB18, and JAM1 mRNA levels were only up-regulated in seedlings with elevated ABA levels (Figure 7).

\section{Phytohormone Levels and Phytohormone-Response Genes in Roots of Infected and Non-infected Neighboring Plants}

Arabidopsis seedlings were grown on plates with low gelrite concentration either in the presence or absence of $P$. indica (Figure S1). Half of the seedlings were infected with the A. brassicae spore suspension (or water as control, marked with a red circle in Figure S1), while the other half remained untreated. After 12 days, the treated (Table 1A) untreated (Tables 1B-D) seedlings were removed for the plates, the roots were separated from the seedling and used for hormone or RNA analyses. From the comparison of the hormone levels shown in Tables 1A,B and those for the different treatments shown in Figure 1B, it is obvious that JA, JA-Ile, and cis-OPDA levels were stimulated by signals traveling through the $P$. indica hyphal network from A. brassicae-infected seedlings to the roots of the non-infected seedlings. The SA level was higher in roots exposed to $P$. indica, and partially repressed when $A$. brassicae-infected seedlings were connected to infected seedlings via the $P$. indica hyphae. Again, $\mathrm{ABA}$ was only upregulated in the roots of non-infected seedlings 

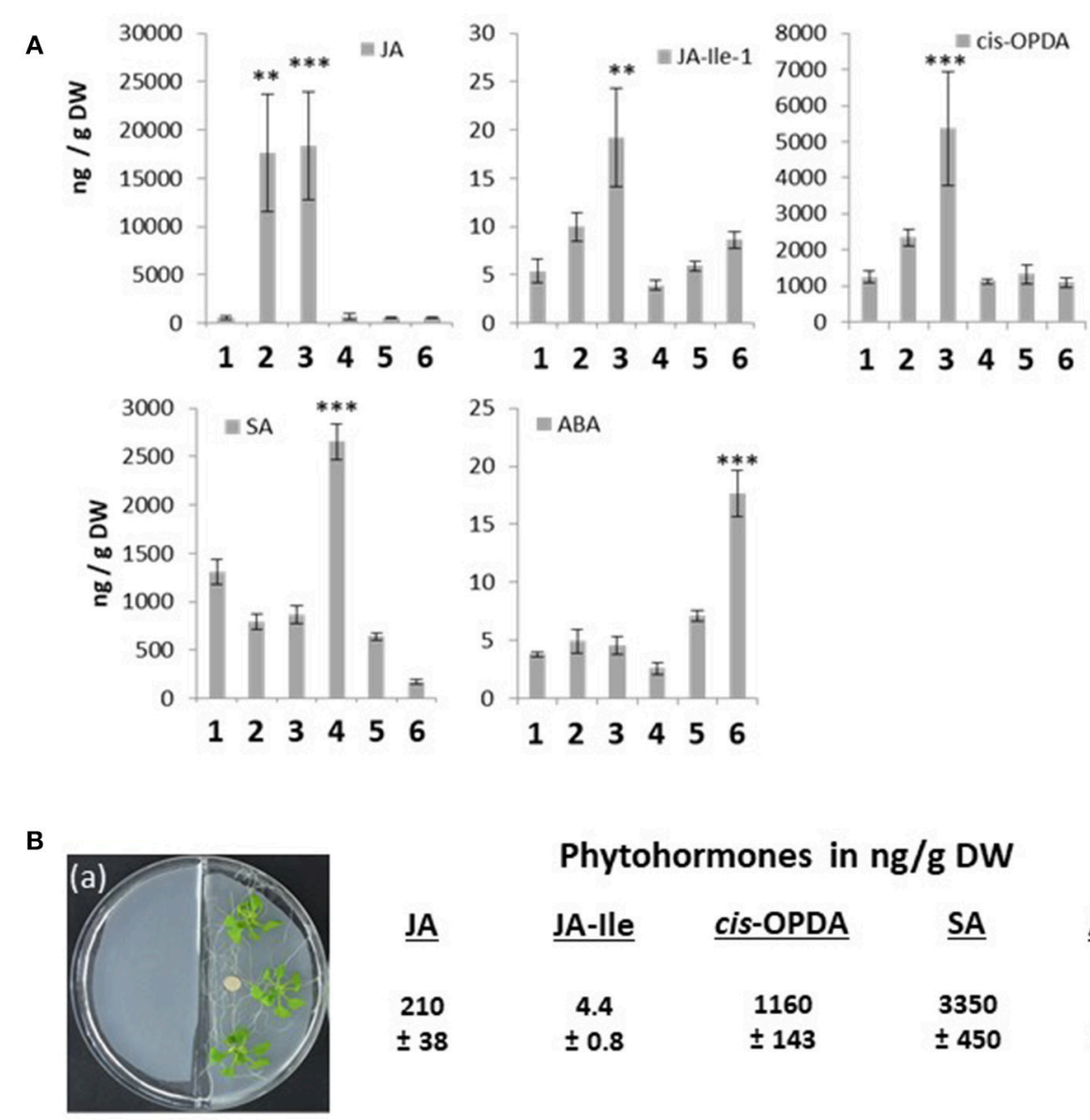

\section{Phytohormones in $\mathrm{ng} / \mathrm{g}$ DW}

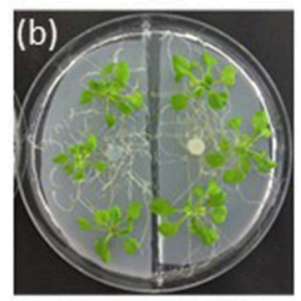

\begin{tabular}{|c|c|c|c|}
\hline JA-lle & cis-OPDA & $\underline{\mathrm{SA}}$ & $\mathrm{ABA}$ \\
\hline 4.4 & 1160 & 3350 & 2.2 \\
\hline \pm 0.8 & \pm 143 & \pm 450 & \pm 0.3 \\
\hline
\end{tabular}

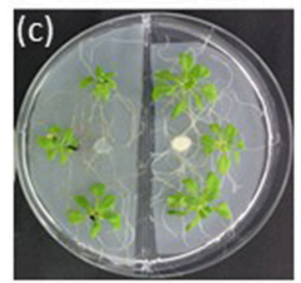

222

$\pm 43$

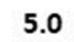

1321

3540

2.4

$\pm 1.0$

$\pm 155$

$\pm 410$

$\pm 0.5$

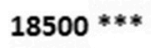

$\pm \mathbf{5 3 0 0}$

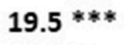

$\pm 5.1$

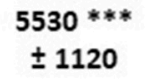

$1510 *$

2.4

$\pm 260 \pm 0.3$

FIGURE 6 | (A) Phytohormone concentrations in ng/g dry weight (DW) in the 6 seedlings (number 1-6) shown in Figure 3A. 1, no treatment; 2, A. brassicae infected material; 3 , seedlings grown next to $A$. brassicae-infected seedlings, 4-6, as 1-3, except that seedlings were connected by a $P$. indica hyphal network. The experimental set-up is shown in Figure 3A. Based on 5 independent experiments, errors represent SEs. Asterisks indicate significant differences to the values for the untreated seedling number 1 , by Student's $t$-test $\left({ }^{\star *} P \leq 0,01{ }^{* * \star} P \leq 0.001\right)$. (B) Split Petri dish experiment with Arabidopsis seedlings. Left chamber: (a) empty, (b) Arabidopsis seedlings, (c) Arabidopsis seedlings infected with A. brassicae spores for 12 days. The hormone levels were determined for the seedlings grown on the right site in the Petri dish, which were grown in the presence of $P$. indica for 12 days. Based on 5 independent experiments, errors represent SEs. Asterisks indicate significant differences to the values of experiment (a), by Student's $t$-test $\left({ }^{*} P \leq 0.1,{ }^{* \star *} P \leq 0.001\right)$.

that were connected to infected seedlings via the $P$. indica hyphal network. This again excludes an information transfer through the gas phase and confirms the requirement of the $P$. indica hyphal network for ABA induction (cf. section Discussion).
Next, we checked the NRT2.5 and RRTF1 mRNA levels in the roots under the four different conditions and compared them to those for the JA-responsive genes PDF1.2, VSP2, and JAR1, the SA-inducible gene $P R-1$ and the ABA-responsive genes $R D 29 A$, 


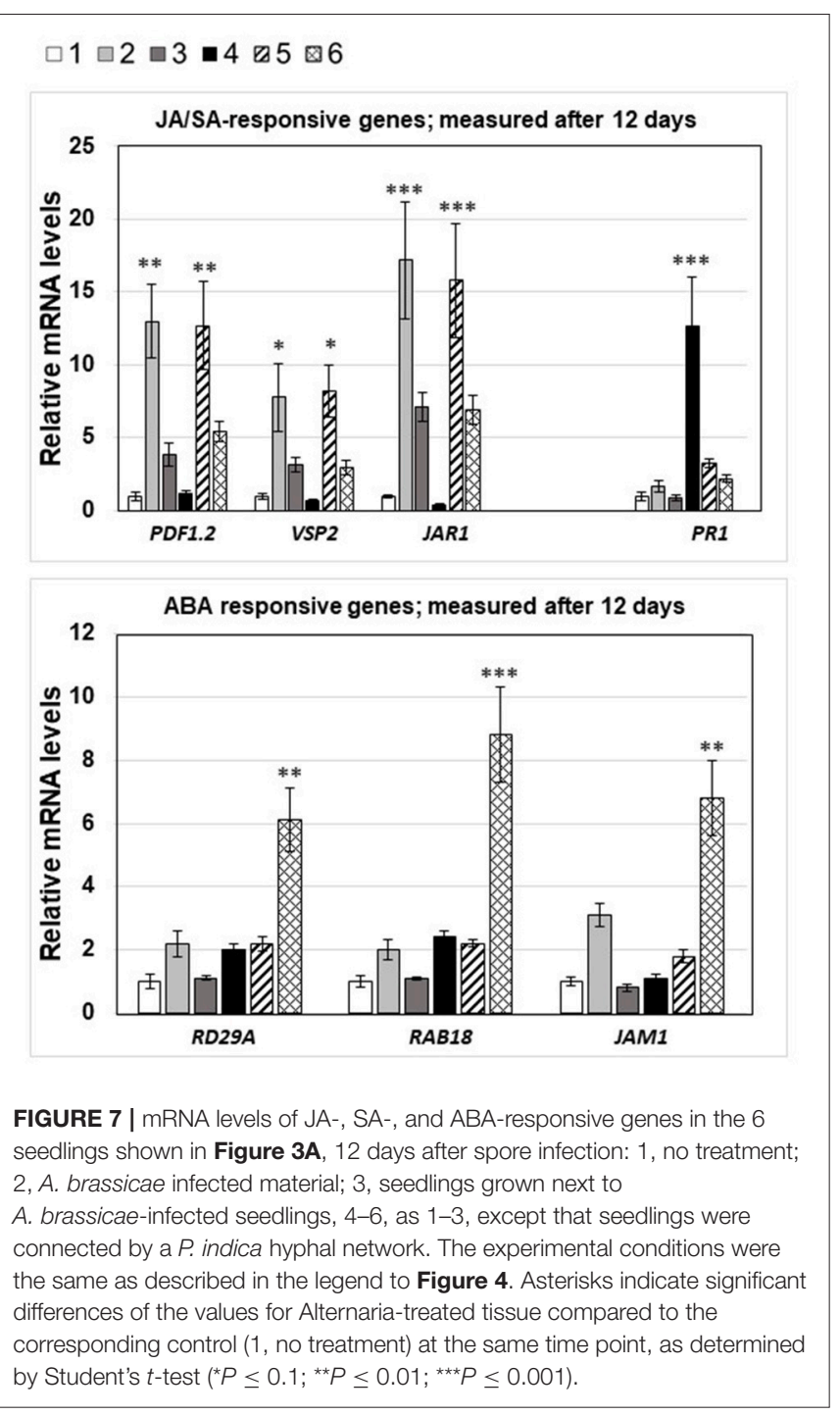

RAB18, and JAM1 (Table 1B). Consistent with the results from Figure 5, the NRT2.5 and RRTF1 mRNA levels were up-regulated in the roots of non-infected seedlings when they were connected to infected seedlings via a $P$. indica hyphal network. This confirms that physical contact via the $P$. indica hyphal network is required for their induction. As shown previously (Kechid et al., 2013), beneficial root-colonizing microbes can induce NRT2.5 expression and a small but not significant stimulation was detectable in the roots of $P$. indica-exposed seedlings (Table 1B). The JA-responsive genes were significantly stimulated in the roots of non-infected seedlings, when they were connected to infected seedlings via a hyphal network. In contrast to the results for the entire seedlings (Figure 6), an information transfer through the air or by chemical mediators in the medium does not play an important role. $P$. indica also stimulated the accumulation of SA and the expression of $P R 1$, and this was inhibited when the seedlings were connected to an A. brassicaeinfected neighboring plant. The ABA-inducible genes were only up-regulated in the roots of non-infected seedlings connected to the infected seedlings via a $P$. indica hyphal network. The response was not observed in two different ABA mutants, aba5-1 and aba2-1 (Tables 1C,D). These data indicate that part of the threat information systemically traveling from the A. brassicae infection site in the leaf to the roots is converted to an ABA stress response in non-infected seedlings after transfer via a $P$. indica hyphal network.

\section{DISCUSSION}

We used NRT2.5 and RRTF1 mRNA levels as readouts to monitor radial and axial signal propagation in Arabidopsis leaves and roots following local infections with A. brassicae spores. These two genes were chosen because we found that their mRNA levels responded systemically to various stresses in pilot experiments, but they are not directly related to phytohormone responses induced by the pathogen. We are aware that many other genes show a similar regulation pattern. The threat information measured at the level of NRT2.5 and RRTF1 is also transferred to neighboring plants when they are connected to the infected plant via a $P$. indica hyphal network. Overall, this information flow is slow (requiring at least 7 days) in this experimental setup, presumably because spore germination requires time and the systemic stimulus increases only slowly with the progression of disease development. However, since these responses are highly dependent on the amount of spores and culture conditions, our experimental set-up is difficult to compare with studies in which a specific stimulus is applied for a defined period of time to a local tissue (cf. section Introduction). Nevertheless, consistent with previous studies (Dengler, 2006; Kiep et al., 2015), we observed that signal propagation requires a connection to the vascular system and becomes weaker or disappears when the pathogen infection is performed on tissues not directly located on major veins (data not shown). In many studies, the distances between the tissue to which a specific stimulus was applied and that, where the response was measured, were quite short (cf. Jayaraman et al., 2014; Choi et al., 2016, and ref. therein). Those studies allow the identification of components which rapidly transfer the information, while our study measured responses after longer time periods and thus included also major metabolomic and developmental changes. Stimulation of RRTF1 is generally faster than that of NRT2.5 (Lezhneva et al., 2014), but the two responses need not necessarily be connected to each other: e.g., fast traveling ROS generated after $A$. brassicae infection could rapidly induce RRTF1 expression (Khandelwal et al., 2008; Matsuo et al., 2015). We have previously demonstrated that RRTF1 amplifies ROS responses in answer to various stress stimuli (Matsuo et al., 2015), and therefore, it is conceivable that up-regulation of this gene might be part of an alarm system to prepare distal parts of a plant and even neighboring plants to respond more rapidly to upcoming threats. In contrast, the slower response of NRT2.5 in distal tissue or neighboring plants could be coupled to metabolic changes in the local and distal tissues associated with $\mathrm{N}$ metabolism. This transporter is involved in nitrate relocation, and the gene could only be activated when the disease progression after $A$. brassicae infection generates a local nitrate shortage, 
although a direct involvement of nitrate transporters in defense responses is also discussed ( $\mathrm{Hu}$ et al., 2009). Several nitrate sensing mechanisms leading to NRT2.5 regulation are possible (cf. Ho et al., 2009; Hu et al., 2009; Krapp et al., 2014), and a nitrate sensing function has been shown for NRT1.1 (Wang et al., 2009) and proposed for NRT2.1 (Orsel et al., 2004; Little et al., 2005; Ohkubo et al., 2017). Ohkubo et al. (2017) showed that shoot-to-root mobile polypeptides are involved in systemic regulation of nitrogen acquisition. Overall, we observed that the entire plant responds to a local pathogen infection on a leaf or the root. The late time points allow us to assay traveling information even over long distances since progression of disease development causes severe local symptoms that should result in appropriate distal responses.

Both genes are also upregulated in non-infected neighboring plants. Plants often communicate with neighboring plants of the same species to alleviate stresses within genetic relatives by transmitting volatile compounds aboveground or a variety of organic and inorganic compounds belowground (Baldwin and Schultz, 1983; Agrawal, 2000; Song et al., 2010, 2014). The experimental set-up shown in Figure $\mathbf{3 A}$ and the split Petri dish experiment (Figure 4) suggested that volatile compounds did not play a role in activating RRTF1 and NRT2.5 expression in uninfected seedlings. However, information transfer via common mycrrohizal networks (CMN) is well known (cf. section Introduction), and $P$. indica as an endophyte with the ability to colonize the roots of all plant species investigated so far is an excellent candidate for the transfer of information to neighboring plants even when they are not belonging to the same species. In our experimental set-up, transfer of threat information to neighboring plants via the $P$. indica hyphal connection is supported by experiments in which this connection is disrupted or the performance of the fungal cells is severely impaired by the application of benomyl. Furthermore, it appears that the information transfer is not mediated by just any fungus, since the two candidates chosen, A. glauca and M. mucedo, cannot replace $P$. indica (Figure 4). The reason for this is unclear, but one might speculate that the cellular connection between fungal and root cells is closer for $P$. indica than the two other investigated fungi. Whether root colonization is important for interplant communication, can be tested by using $P$. indica strains in combination with various (mutant) plants altered in colonization level (Lahrmann et al., 2013; Rafiqi et al., 2013; Akum et al., 2015; Li et al., 2016). Different from CMN with mycorrhizal fungi, invasion of $P$. indica hyphae into root cells is rare (Figure 3B), and most of the hyphae are surrounding the root or are attached to root cells. Therefore, an information transfer via chemical mediators between the fungal and host cell is likely. However, this requires further investigation.

Our data suggest that the neighboring plants respond to the threat information by stimulating accumulation of ABA, a stress hormone that is not up-regulated in infected plants. The most straightforward interpretation of these data is that A. brassicae first induces a specific JA stress response in the infected local leaf. This information then travels to systemic roots and is further transferred to neighboring plants via the $P$. indica hyphal network where specific information is converted to general stress information. This interpretation is consistent with the fact that fungi do not contain a JA-specific defense pathway comparable to that in plants, although fungal enzymes can manipulate plant JA metabolism (cf. Patkar et al., 2015). The shift in the hormone levels and expression profiles from JA-responsive genes in the roots of the infected plant to ABA-responsive genes in the roots of the neighboring plant provides us with important tools to further study how this information is translocated though the fungal hyphae. The observation that the JA-specific response to the pathogen in the infected plant is converted to an ABA response in the non-infected neighboring plant is an interesting observation that can be experimentally approached in many ways. ABA has been shown to participate in systemic signaling in response to abiotic stress (Mittler and Blumwald, 2015), participates in the integration of multiple stresses (Nguyen et al., 2016), and cross-talks with defense- and stress-related hormones including JA (Nakata et al., 2013; Verma et al., 2016). Furthermore, the ABA level is up-regulated in response to multiple stresses (e.g., Lievens et al., 2017) and ABA signaling components integrate a wide range of information relevant for stress responses, adaptation and developmental processes. Therefore, it is a good candidate to respond to signals from the fungal hyphae which carry more general stress information due to its contact to a stress-exposed plant. The microbe is unable to understand a specific JA-dependent stress response of the plant, but appears to transmit the threat information, which is then decoded at the receiving plant side and activates a general and not stimulus-related stress response which includes ABA. Interestingly, Hettenhausen et al. (2017) showed recently that host plants connected by Cuscuta bridges transmit systemic herbivory signals to unattacked plants. Here interplant signaling is largely dependent on JA signaling and herbivore attack on one host plant elevates defense metabolites in the other connected non-attacked host, resulting in enhanced resistance over longer distances $(>100 \mathrm{~cm})$. Although interplant connection occurs via a plant bridge in this study, comparison of this system to Arabidopsis with a $P$. indica hyphal network might help to understand how a specific JA information is further translocated to neighboring plants.

We observed a strong antagonistic effect of JA, JA-Ile, and cis-OPDA levels, which are induced by $A$. brassicae, on SA responding to $P$. indica colonization (Figures 5, 6B, cf. also Michal Johnson et al., 2014). In the absence of $P$. indica, A. brassicae induces local and systemic JA, JAIle, and cis-OPDA accumulation, and this stimulation is also detectable in neighboring plants irrespective of whether they are connected to the infected plants or not. In all cases, the regulation on the phytorhomone level correlated with the response of the respective phytohormone-responsive genes (Figures 6, 7). Suppression of the JA-responsive pathway by SA is predominantly regulated at the level of gene transcription (Van der Does et al., 2010), and not by JA biosynthesis itself, as the SA-mediated suppression of MeJA-induced PDF1.2 was intact in the JA biosynthesis mutant aos/dde2 (Leon-Reyes et al., 2010). SA antagonizes JA signaling downstream of COI1, possibly by interfering with JA-regulated transcription factors. Further, several WRKY and TGA transcription factors have been shown to be important for suppression of the JA-responsive pathway by SA (Li et al., 2004, 2006; Pieterse et al., 2012; Gimenez-Ibanez and 
Solano, 2013; Caarls et al., 2015) have shown that the SA-induced WRKY70 suppressed MeJA-induced PDF1.2 expression.

Cosme et al. (2016) showed that $P$. indica helps rice plants to tolerate root herbivory through changes in JA signaling. In their study, JA is transported from herbivore-damaged leaves to roots, as first shown by Zhang and Baldwin (1997) using $\left[2-{ }^{14} \mathrm{C}\right] \mathrm{JA}$. Jimenez-Aleman et al. (2015) also demonstrated that a labeled precursor of JA was able to travel from a wounded local tissue to unwounded systemic leaves when applied exogenously. These studies support that jasmonates can be transported and thus transfer information within the plant body. Since jasmonates as well as jasmonate-responsive genes are also up-regulated in noninfested plants not connected to infested plants via a $P$. indica hyphal network, our data suggest that an additional information transfer through the gas phase is likely. However, we failed to identify volatiles responsible for this response. Vahabi et al. (2013) showed that $P$. indica can grow in host roots even when they contain elevated jasmonate levels. This might be important for $P$. indica growth under our conditions and its efficient repression of jasmonate accumulation.

Connecting plants by a $P$. indica hyphal network resulted in elevated ABA levels and expression of ABA-responsive genes in non-infested plants (Figure 6, Table 1). Also Peskan-Berghöfer et al. (2015) showed that elevated ABA levels triggered by osmotic stress promoted $P$. indica colonization of the roots, without impairing plant fitness. Furthermore, sustained exposure to ABA muted defense response in roots and thereby made them more accessible for the mutualist. Again, these data are consistent with our observations that non-infested seedlings with elevated ABA levels contain low jasmonate levels.

Taken together, JA-related threat information can be transferred to as yet unattacked neighboring plants via a $P$. indica hyphal network. We propose that this information

\section{REFERENCES}

Agrawal, A. A. (2000). Communication between plants: this time it's real. Trends Ecol. Evol. 15:446. doi: 10.1016/S0169-5347(00)01987-X

Akum, F. N., Steinbrenner, J., Biedenkopf, D., Imani, J., and Kogel, K.-H. (2015). The Piriformospora indica effector PIIN_08944 promotes the mutualistic Sebacinalean symbiosis. Front. Plant Sci. 6:906. doi: 10.3389/fpls.2015.00906

Arimura, G., Ozawa, R., Shimoda, T., Nishioka, T., Boland, W., and Takabayashi, J. (2000). Herbivory-induced volatiles elicit defence genes in lima bean leaves. Nature 406, 512-515. doi: 10.1038/35020072

Baldwin, I. T., Halitschke, R., Paschold, A., von Dahl, C. C., and Preston, C. A. (2006). Volatile signaling in plant-plant interactions: "talking trees" in the genomics era. Science 311, 812-815. doi: 10.1126/science.1118446

Baldwin, I. T., Kessler, A., and Halitschke, R. (2002). Volatile signaling in plantplant-herbivore interactions: what is real? Curr. Opin. Plant Biol. 5, 351-354. doi: 10.1016/S1369-5266(02)00263-7

Baldwin, I. T., and Schultz, J. C. (1983). Rapid changes in tree leaf chemistry induced by damage: evidence for communication between plants. Science 221, 277-279. doi: 10.1126/science.221.4607.277

Barto, K. E., Weidenhamer, J. D., Cipollini, D., and Rillig, M. C. (2012). Fungal superhighways: do common mycorrhizal networks enhance below ground communication? Trends Plant Sci. 17, 633-637. doi: 10.1016/j.tplants.2012.06.007

Bingham, M. A., and Simard, S. W. (2011). Do mycorrhizal network benefits to survival and growth of interior Douglas-fir seedlings increase with soil moisture stress? Ecol. Evol. 1, 306-316. doi: 10.1002/ece3.24 transfer is associated with the loss of specific threat information, since the A. brassicae-specific JA response induces a more general ABA-dependent stress response in the connected plant. Combination of phytohormone mutants with-omics approaches will help to elucidate how the threat information is transferred from one plant to the other via the $P$. indica hyphal network.

\section{AUTHOR CONTRIBUTIONS}

$\mathrm{KV}$ : designed and performed the experiments described in Figure 2A; MR: performed the phytohormone analyses; SS: analysis of hormone-responsive genes; JJ: designed the experiments for systemic signaling; AF: performed the microscopic studies; MM: designed and performed RRTF1 experiments; IS, JG, and RO: supervised the project; RO: wrote the paper. All authors read and approved the final version of the manuscript.

\section{ACKNOWLEDGMENTS}

Work was supported by the DFG (CRC1127 and project OE13332-1) and the Jena School of Microbial Communication. We thank Claudia Röppischer and Sarah Mußbach for help with RNA extractions and qPCR analyses. We thank Sedigheh Karimi Dorcheh and Johannes Wöstemeyer (FSU Jena) for providing fungus material.

\section{SUPPLEMENTARY MATERIAL}

The Supplementary Material for this article can be found online at: https://www.frontiersin.org/articles/10.3389/fpls.2018. 00626/full\#supplementary-material

Bingham, M. A., and Simard, S. W. (2012). Mycorrhizal networks affect ectomycorrhizal fungal community similarity between conspecific trees and seedlings. Mycorrhiza 22, 317-326. doi: 10.1007/s00572-011-0406-y

Booth, M. G., and Hoeksema, J. D. (2010). Mycorrhizal networks counteract competitive effects of canopy trees on seedling survival. Ecology 91, 2294-2302. doi: 10.1890/09-1139.1

Caarls, L., Pieterse, C. M., and Van Wees, S. C. (2015). How salicylic acid takes transcriptional control over jasmonic acid signaling. Front. Plant Sci. 6:170. doi: 10.3389/fpls.2015.00170

Camehl, I., Drzewiecki, C., Vadassery, J., Shahollari, B., Sherameti, I., Forzani, C., et al. (2011). The OXI1 kinase pathway mediates Piriformospora indica-induced growth promotion in Arabidopsis. PLoS Pathog. 7:e1002051. doi: 10.1371/journal.ppat.1002051

Cao, H., Glazebrook, J., Clarke, J. D., Volko, S., and Dong, X. N. (1997). The Arabidopsis NPR1 gene that controls systemic acquired resistance encodes a novel protein containing ankyrin repeats. Cell 88, 57-63. doi: 10.1016/S0092-8674(00)81858-9

Chien, P. S., Chiang, C. B., Wang, Z., and Chiou, T. J. (2017). MicroRNA-mediated signaling and regulation of nutrient transport and utilization. Curr. Opin. Plant Biol. 39, 73-79. doi: 10.1016/j.pbi.2017.06.007

Choi, W. G., Hilleary, R., Swanson, S. J., and Kim, S. H. (2016). Gilroy S: rapid, long-distance electrical and calcium signaling in plants. Annu. Rev. Plant Biol. 67, 287-307. doi: 10.1146/annurev-arplant-043015-112130

Choi, W. G., Swanson, S. J., and Gilroy, S. (2012). High-resolution imaging of $\mathrm{Ca}^{2+}$, redox status, ROS and pH using GFP biosensors. Plant J. 70, 118-128. doi: 10.1111/j.1365-313X.2012.04917.x 
Chopin, F., Orsel, M., Dorbe, M. F., Chardon, F., Truong, H. N., Miller, A. J., et al. (2007). The Arabidopsis ATNRT2.7 nitrate transporter controls nitrate content in seeds. Plant Cell 19, 1590-1602. doi: 10.1105/tpc.107.050542

Christmann, A., Weiler, E. W., Steudle, E., and Grill, E. (2007). A hydraulic signal in root-to-shoot signalling of water shortage. Plant J. 52, 167-174. doi: 10.1111/j.1365-313X.2007.03234.x

Cosme, M., Lu, J., Erb, M., Stout, M. J., Franken, P., and Wurst, S. (2016). A fungal endophyte helps plants to tolerate root herbivory through changes in gibberellin and jasmonate signaling. New Phytol. 1, 1065-1076. doi: $10.1111 /$ nph.13957

Dechorgnat, J., Patrit, O., Krapp, A., Fagard, M., and Daniel-Vedele, F. (2012). Characterization of the Nrt2.6 gene in Arabidopsis thaliana: a link with plant response to biotic and abiotic stress. PLoS ONE 7:e42491. doi: 10.1371/journal.pone.0042491

Dempsey, D. A., and Klessig, D. F. (2012). SOS - too many signals for systemic acquired resistance? Trends Plant Sci. 17, 538-17545. doi: $10.1016 /$ j.tplants.2012.05.011

Dengler, N. G. (2006). The shoot apical meristem and development of vascular architecture. Can. J. Bot. 84, 1660-1671. doi: 10.1139/b06-126

de Ollas, C., and Dodd, I. C. (2016). Physiological impacts of ABAJA interactions under water-limitation.. Plant Mol. Biol. 91, 641-650. doi: 10.1007/s11103-016-0503-6

Di, X., Takken, F. L. W., and Tintor, N. (2016). How phytohormones shape interactions between plants and the soil-borne fungus Fusarium oxysporum. Front. Plant Sci. 7:170. doi: 10.3389/fpls.2016.00170

Dickie, I. A., Koide, R. T., and Steiner, K. C. (2005a). Influences of established trees on mycorrhizas, nutrition, and growth of Quercus rubra seedlings. Ecol. Monogr. 72, 505-521. doi: 10.1890/0012-9615(2002)072[0505:IOETOM]2.0. $\mathrm{CO} ; 2$

Dickie, I. A., Schnitzer, S. A., Reich, P. B., and Hobbie, S. E. (2005b). Spatially disjunct effects of co-ccurring competition and facilitation. Ecol. Lett. 8, 1191-1200. doi: 10.1111/j.1461-0248.2005.00822.x

Dong, S., Tian, Z., Chen, P. J., Senthil, K. R., Shen, C. H., Cai, D., et al. (2013). The maturation zone is an important target of Piriformospora indica in Chinese cabbage roots. J. Exp. Bot. 64, 4529-4450. doi: 10.1093/jxb/ert265

Eason, W. R., Newman, E. I., and Chuba, P. N. (1991). Specificity of interplant cycling of phosphorus: the role of mycorrhizas. Plant Soil 137, 267-274. doi: 10.1007/BF00011205

Erb, M., Lenk, C., Degenhardt, J., and Turlings, T. C. (2009). The underestimated role of roots in defense against leaf attackers. Trends Plant Sci. 14, 653-659. doi: 10.1016/j.tplants.2009.08.006

Fagard, M., Launay, A., Clément, G., Courtial, J., Dellagi, A., Farjad, M., et al. (2014). Nitrogen metabolism meets phytopathology. J. Exp. Bot. 65, 5643-5656. doi: $10.1093 / \mathrm{jxb} / \mathrm{eru} 323$

Farmer, E. E., Mousavi, S., and Lenglet, A. (2013). Leaf numbering for experiments on long distance signalling in Arabidopsis. Nat. Prot. Exchange. doi: $10.1038 /$ protex.2013.071

Finkelstein, R. R., and Lynch, T. J. (2000). The Arabidopsis abscisic acid response gene $A B I 5$ encodes a basic leucine rich repeat transcription factor. Plant Cell 12, 599-609. doi: 10.1105/tpc.12.4.599

Fitter, A. H., Graves, J. D., Watkins, N. K., Robinson, D., and Scrimgeour, C. (1998). Carbon transfer between plants and its control in networks of arbuscular mycorrhizas. Funct. Ecol. 12, 406-412.

$\mathrm{Fu}$, Z. Q., and Dong, X. (2013). Systemic acquired resistance: turning local infection into global defense. Annu. Rev. Plant Biol. 64, 839-863. doi: 10.1146/annurev-arplant-042811-105606

Gayomba, S. R., Zhai, Z., Jung, H. I., and Vatamaniuk, O. K. (2015). Local and systemic signaling of iron status and its interactions with homeostasis of other essential elements. Front. Plant Sci. 6:716. doi: 10.3389/fpls.2015.00716

Gilroy, S., Suzuki, N., Miller, G., Choi, W.-G., Toyota, M., Devireddy, A. R., et al. (2014). A tidal wave of signals: calcium and ROS at the forefront of rapid systemic signaling. Trends Plant Sci. 19, 623-630. doi: 10.1016/j.tplants.2014.06.013

Gimenez-Ibanez, S., and Solano, R. (2013). Nuclear jasmonate and salicylate signaling and crosstalk in defense against pathogens. Front. Plant Sci. 4:72. doi: $10.3389 /$ fpls.2013.00072
Giovannetti, M., Avio, L., Fortuna, P., Pellegrino, E., Sbrana, C., and Strani, P. (2006). At the root of the wood wide web: self recognition and non-self incompatibility in mycorrhizal networks. Plant Signal. Behav. 1, 1-5.

Guillemette, T., Sellam, A., and Simoneau, P. (2004). Analysis of a nonribosomal peptide synthetase gene from Alternaria brassicae and flanking genomic sequences. Curr. Genet. 45, 214-224. doi: 10.1007/s00294-003-0479-z

Hannapel, D. J., Sharma, P., and Lin, T. (2013). Phloem-mobile messenger RNAs and root development. Front. Plant Sci. 4:257. doi: 10.3389/fpls.2013.00257

Harrach, B. D., Baltruschat, H., Barna, B., Fodor, J., and Kogel, K.-H. (2013). The mutualistic fungus Piriformospora indica protects barley roots from a loss of antioxidant capacity caused by the necrotrophic pathogen Fusarium culmorum. Mol. Plant-Microbe Interact. 26, 599-605. doi: 10.1094/MPMI-09-12-0216-R

He, X. H., Xu, M. G., Qiu, G. Y., and Zhou, J. B. (2009). Use of ${ }^{15} \mathrm{~N}$ stable isotope to quantify nitrogen transfer between mycorrhizal plants. J. Plant Ecol. 2, 107-118. doi: 10.1093/jpe/rtp015

Hedrich, R., Salvador-Recatalà, V., and Dreyer, I. (2016). Electrical wiring and long-distance plant communication. Trends Plant Sci. 21, 376-387. doi: 10.1016/j.tplants.2016.01.016

Herrera-Vásquez, A., Carvallo, L., Blanco, F., Tobar, M., Villarroel-Candia, E., Vicente-Carbajosa, J., et al. (2015). Transcriptional control of glutaredoxin GRXC9 expression by a salicylic acid-dependent and NPR1Independent pathway in arabidopsis. Plant Mol. Biol. Rep. 33, 624-637. doi: 10.1007/s11105-014-0782-5

Hettenhausen, C., Li, J., Zhuang, H., Sun, H., Xu, Y., Qi, J., et al. (2017). Stem parasitic plant Cuscuta australis (dodder) transfers herbivory-induced signals among plants. Proc. Natl. Acad. Sci. U.S.A. 114, E6703-E6709. doi: $10.1073 /$ pnas. 1704536114

Hilbert, M., Voll, L. M., Ding, Y., Hofmann, J., Sharma, M., and Zuccaro, A. (2012). Indole derivative production by the root endophyte Piriformospora indica is not required for growth promotion but for biotrophic colonization of barley roots. New Phytol. 196, 520-534. doi: 10.1111/j.1469-8137.2012.04275.x

Ho, C. H., Lin, S. H., Hu, H. C., and Tsay, Y. F. (2009). CHL1 functions as a nitrate sensor in plants. Cell 18, 1184-1194. doi: 10.1016/j.cell.2009.07.004

Hu, H. C., Wang, Y. Y., and Tsay, Y. F. (2009). AtCIPK8, a CBL-interacting protein kinase, regulates the low-affinity phase of the primary nitrate response. Plant $\mathrm{J}$. 57, 264-278. doi: 10.1111/j.1365-313X.2008.03685.x

Huber, A. E., and Bauerle, T. L. (2016). Long-distance plant signaling pathways in response to multiple stressors: the gap in knowledge. J. Exp. Bot. 67, 2063-2079. doi: 10.1093/jxb/erw099

Jayaraman, D., Gilroy, S., and Ané, J. M. (2014). Staying in touch: mechanical signals in plant-microbe interactions. Curr. Opin. Plant Biol. 20, 104-109. doi: 10.1016/j.pbi.2014.05.003

Jimenez-Aleman, G. H., Scholz, S. S., Heyer, M., Reichelt, M., Mithöfer, A., and Boland, W. (2015). Synthesis, metabolism and systemic transport of a fluorinated mimic of the endogenous jasmonate precursor OPC-8:0. Biochim. Biophys. Acta 1851, 1545-1553. doi: 10.1016/j.bbalip.2015.09.002

Kazan, K., and Manners, J. M. (2012). MYC2: the master in action. Mol. Plant 6, 686-703. doi: $10.1093 / \mathrm{mp} / \mathrm{sss} 128$

Kechid, M., Desbrosses, G., Rokhsi, W., Varoquaux, F., Djekoun, A., and Touraine, B. (2013). The NRT2.5 and NRT2.6 genes are involved in growth promotion of Arabidopsis by the plant growth-promoting rhizobacterium (PGPR) strain Phyllobacterium brassicacearum STM196. New Phytol. 198, 514-524. doi: 10.1111/nph.12158

Khandelwal, A., Elvitigala, T., Ghosh, B., and Quatrano, R. S. (2008). Arabidopsis transcriptome reveals control circuits regulating redox homeostasis and the role of an AP2 transcription factor. Plant Physiol. 148, 2050-2058. doi: $10.1104 /$ pp.108.128488

Kiep, V., Vadassery, J., Lattke, J., Maaß, J. P., Boland, W., Peiter, E., et al. (2015). Systemic cytosolic $\mathrm{Ca}(2+)$ elevation is activated upon wounding and herbivory in Arabidopsis. New Phytol. 207, 996-1004. doi: 10.1111/nph.13493

Kliebenstein, D. J. (2014). Orchestration of plant defense systems: genes to populations. Trends Plant Sci. 19, 250-255. doi: 10.1016/j.tplants.2014.01.003

Kotur, Z., and Glass, A. D. (2014). A $150 \mathrm{kDa}$ plasma membrane complex of AtNRT2.5 and AtNAR2.1 is the major contributor to constitutive high-affinity nitrate influx in Arabidopsis thaliana. Plant Cell Environ. 38, 1490-1502. doi: $10.1111 /$ pce. 12496 
Kramell, R., Schmidt, J., Schneider, G., Sembdner, G., and Schreiber, K. (1988). Synthesis of n-(jasmonoyl)-amino acid conjugates. Tetrahedron 44, 5791-5807. doi: 10.1016/S0040-4020(01)81437-X

Krapp, A., David, L. C., Chardin, C., Girin, T., Marmagne, A., Leprince, A.-S., et al. (2014). Nitrate transport and signalling in Arabidopsis. J. Exp. Bot. 5, 789-798. doi: $10.1093 / \mathrm{jxb} / \mathrm{eru001}$

Kudla, J., Batistič, O., and Hashimoto, K. (2010). Calcium signals: the lead currency of plant information processing. Plant Cell 22, 541-563. doi:10.1105/tpc. 109.072686

Lacombe, B., and Achard, P. (2016). Long-distance transport of phytohormones through the plant vascular system. Curr. Opin. Plant Biol. 34, 1-8. doi: 10.1016/j.pbi.2016.06.007

Lahrmann, U., Ding, Y., Banhara, A., Rath, M., Hajirezaei, M. R., Döhlemann, S., et al. (2013). Host-related metabolic cues affect colonization strategies of a root endophyte. Proc. Natl. Acad. Sci. U.S.A. 110, 13965-13970. doi: 10.1073/pnas.1301653110

Leake, J., Johnson, D., Donnelly, D., Muckle, G., Boddy, L., and Read, D. (2004). Networks of power and influence, the role of mycorrhizal mycelium in controlling plant communities and agroecosystem functioning. Can. J. Bot. 82, 1016-1045. doi: 10.1139/b04-060

Lemoine, R., La Camera, S., Atanassova, R., Dédaldéchamp, F., Allario, T., Pourtau, N., et al. (2013). Source-to-sink transport of sugar and regulation by environmental factors. Front. Plant Sci. 24:272. doi: 10.3389/fpls.2013.00272

Leon-Reyes, A., Du, Y., Koornneef, A., Proietti, S., Körbes, A. P., Memelink, J., Pieterse, C. M., Ritsema, T. (2010). Ethylene signaling renders the jasmonate response of Arabidopsis insensitive to future suppression by salicylic Acid. Mol. Plant Microbe Interact. 23, 187-197. doi: 10.1094/MPMI-23-2-0187

Lezhneva, L., Kiba, T., Feria-Bourrellier, A. B., Lafouge, F., Boutet-Mercey, S., Zoufan, P., et al. (2014). The Arabidopsis nitrate transporter NRT2.5 plays a role in nitrate acquisition and remobilization in nitrogen-starved plants. Plant J. 80, 230-241. doi: $10.1111 /$ tpj.12626

Li, J., Brader, G., Kariola, T., and Tapio Palva, E. (2006). WRKY70 modulates the selection of signaling pathways in plant defense. Plant J. 46, 477-491. doi: 10.1111/j.1365-313X.2006.02712.x

Li, J., Brader, G., and Tapio Palva, E. (2004). The WRKY70 transcription factor: a node of convergence for jasmonate-mediated and salicylate-mediated signals in plant defense. Plant Cell. 16, 319-331. doi: 10.1105/tpc.016980

Li, L., Chen, X., Ma, C., Wu, H., and Qi, S. (2016). Piriformospora indica requires kaurene synthase activity for successful plant colonization. Plant Physiol. Biochem. 102, 151-160. doi: 10.1016/j.plaphy.2016.02.017

Li, Y., Krouk, G., Coruzzi, G. M., and Ruffel, S. (2014). Finding a nitrogen niche: a systems integration of local and systemic nitrogen signalling in plants. J. Exp. Bot. 65, 5601-5610. doi: 10.1093/jxb/eru263

Lievens, L., Pollier, J., Goossens, A., Beyaert, R., and Staal, J. (2017). Abscisic acid as pathogen effector and immune regulator. Front. Plant Sci. 8:587. doi: 10.3389/fpls.2017.00587

Little, D. Y., Rao, H., Oliva, S., Daniel-Vedele, F., Krapp, A., and Malamy, J. E. (2005). The putative high-affinity nitrate transporter NRT2.1 represses lateral root initiation in response to nutritional cues. Proc. Natl. Acad. Sci. U.S.A. 102, 13693-13698. doi: 10.1073/pnas.0504219102

Ma, Q., Tang, R. J., Zheng, X. J., Wang, S. M., and Luan, S. (2015). The calcium sensor CBL7 modulates plant responses to low nitrate in Arabidopsis. Biochem. Biophys. Res. Commun. 468, 59-65. doi: 10.1016/j.bbrc.2015.10.164

Mantelin, S., Desbrosses, G., Larcher, M., Tranbarger, T. J., Cleyet-Marel, J. C., and Touraine, B. (2006). Nitrate-dependent control of root architecture and N nutrition are altered by a plant growth-promoting Phyllobacterium sp. Planta 223, 591-603. doi: 10.1007/s00425-005-0106-y

Matsui, K. (2006). Green leaf volatiles: hydroperoxide lyase pathway of oxylipin metabolism. Curr. Opin. Plant Biol. 9, 274-280. doi: 10.1016/j.pbi.2006.03.002

Matsuo, M., Johnson, J. M., Hieno, A., Tokizawa, M., Nomoto, M., Tada, Y., et al. (2015). High REDOX RESPONSIVE TRANSCRIPTION FACTOR1 levels result in accumulation of reactive oxygen species in Arabidopsis thaliana shoots and roots. Mol. Plant 8, 1253-1273 doi: 10.1016/j.molp.2015.03.011

Matsuo, M., and Oelmüller, R. (2015). REDOX RESPONSIVE TRANSCRIPTION FACTOR1 is involved in age-dependent and systemic stress signaling. Plant Signal. Behav. 10:e1051279. doi: 10.1080/15592324.2015.1051279

McGuire, K. L. (2007). Common MNs may maintain monodominance in a tropical rain forest. Ecology 88, 567-574. doi: 10.1890/05-1173
Michal Johnson, J., Reichelt, M., Vadassery, J., Gershenzon, J., and Oelmüller, R. (2014). An Arabidopsis mutant impaired in intracellular calcium elevation is sensitive to biotic and abiotic stress. BMC Plant Biol. 14:162. doi: 10.1186/1471-2229-14-162

Miller, G., Schlauch, K., Tam, R., Cortes, D., Torres, M. A., Shulaev, V., et al. (2009). The plant NADPH oxidase RBOHD mediates rapid systemic signaling in response to diverse stimuli. Sci. Signal. 2:ra45. doi: 10.1126/scisignal.2000448

Mittler, R., and Blumwald, E.: (2015). The roles of ROS and ABA in systemic acquired acclimation. Plant Cell 27, 64-70. doi: 10.1105/tpc.114.133090

Mousavi, S. A. R., Chauvin, A., Pascaud, F., Kellenberger, S., and Farmer, E. E. (2013). GLUTAMATE RECEPTOR-LIKE genes mediate leaf-to-leaf wound signalling. Nature 500, 422-426. doi: 10.1038/nature 12478

Nakata, M., Mitsuda, N., Herde, M., Koo, A. J., Moreno, J. E., Suzuki, K., et al. (2013). A bHLH-type transcription factor, ABA-INDUCIBLE BHLHTYPE TRANSCRIPTION FACTOR/JA-ASSOCIATED MYC2-LIKE1, acts as a repressor to negatively regulate jasmonate signaling in arabidopsis. Plant Cell. 25, 1641-1656. doi: 10.1105/tpc.113.111112

Nguyen, D., Rieu, I., Mariani, C., and van Dam, N. M. (2016). How plants handle multiple stresses: hormonal interactions underlying responses to abiotic stress and insect herbivory. Plant Mol Biol. 91, 27-40. doi: 10.1007/s11103-016-0481-8

Niinemets, U., Kännaste, A., and Copolovici, L. (2013). Quantitative patterns between plant volatile emissions induced by biotic stresses and the degree of damage. Front. Plant Sci. 4:262. doi: 10.3389/fpls.2013.00262

Ohkubo, Y., Tanaka, M., Tabata, R., Ogawa-Ohnishi, M., and Matsubayashi, Y. (2017). Shoot-to-root mobile polypeptides involved in systemic regulation of nitrogen acquisition. Nat. Plants 3:17029. doi: 10.1038/nplants.2017.29

Okamoto, S., Tabata, R., and Matsubayashi, Y. (2016). Long-distance peptide signaling essential for nutrient homeostasis in plants. Curr. Opin. Plant Biol. 34, 35-40. doi: 10.1016/j.pbi.2016.07.009

Orsel, M., Eulenburg, K., Krapp, A., and Daniel-Vedele, F. (2004). Disruption of the nitrate transporter genes AtNRT2.1 and AtNRT2.2 restricts growth at low external nitrate concentration. Planta 219, 714-721. doi: 10.1007/s00425-004-1266-x

Patkar, R. N., Benke, P. O., Qu, Z., Yi, Y., Chen, C., Yang, F., et al. (2015). A fungal monooxygenase-derived jasmonate attenuates host innate immunity Nature Chem. Biol. 11, 733-740. doi: 10.1038/nchembio.1885

Paul, A. L., Semer, C., Kucharek, T., and Ferl, R. J. (2001). The fungicidal and phytotoxic properties of benomyl and PPM in supplemented agar media supporting transgenic Arabidopsis plants for a Space Shuttle flight experiment. Appl. Microbiol. Biotech. 5, 480-485. doi: 10.1007/s002530000521

Peškan-Berghöfer, T., Shahollari, B., Giong, P. H., Hehl, S., Markert, C., Blanke, V., et al. (2004). Association of Piriformospora indica with Arabidopsis thaliana roots represents a novel system to study beneficial plant-microbe interactions and involves early plant protein modifications in the endoplasmic reticulum and at the plasma membrane. Physiol. Plant. 122, 465-477. doi: 10.1111/j.1399-3054.2004.00424.x

Peskan-Berghöfer, T., Vilches-Barro, A., Müller, T. M., Glawischnig, E., Reichelt, M., Gershenzon, J., et al. (2015). Sustained exposure to abscisic acid enhances the colonization potential of the mutualist fungus Piriformospora indica on Arabidopsis thaliana roots. New Phytol. 208, 873-886. doi: 10.1111/nph.13504

Pieterse, C. M., Van der Does, D., Zamioudis, C., Leon-Reyes, A., and Van Wees, S.C. (2012). Hormonal modulation of plant immunity. Annu. Rev. Cell Dev. Biol. 28, 489-521. doi: 10.1146/annurev-cellbio-092910-154055

Pieterse, C. M., Zamioudis, C., Berendsen, R. L., Weller, D. M., Van Wees, S. C., and Bakker, P. A. (2014). Induced systemic resistance by beneficial microbes. Annu. Rev. Phytopathol. 52, 347-375. doi: 10.1146/annurev-phyto-082712-102340

Puga, M. I., Rojas-Triana, M., de Lorenzo, L., Leyva, A., Rubio, V., and Paz-Ares, J. (2017). Novel signals in the regulation of Pi starvation responses in plants: facts and promises. Curr. Opin. Plant Biol. 39, 40-49. doi: 10.1016/j.pbi.2017.05.007

Rafiqi, M., Jelonek, L., Akum, N. F., Zhang, F., and Kogel, K. H. (2013). Effector candidates in the secretome of Piriformospora indica, a ubiquitous plantassociated fungus. Front. Plant Sci. 11:228. doi: 10.3389/fpls.2013.00228

Reimer-Michalski, E. M., and Conrath, U. (2016). Innate immune memory in plants. Semin. Immunol. 28, 319-327. doi: 10.1016/j.smim.2016.05.006

Ren, L. X., Lou, Y., Zhang, N., Zhu, X., Hao, W., Sun, S., et al. (2013). Role of arbuscular mycorrhizal network in carbon and phosphorus transfer between plants. Biol. Fertil. Soils 49, 3-11. doi: 10.1007/s00374-012-0689-y 
Robert-Seilaniantz, A., Grant, M., and Jones, J. D. (2011). Hormone crosstalk in plant disease and defense: more than just jasmonatesalicylate antagonism. Annu. Rev. Phytopathol. 49, 317-343. doi: 10.1146/annurev-phyto-073009-114447

Salvador-Recatalà, V., Tjallingii, W. F., and Farmer, E. E. (2014). Realtime, in vivo intracellular recordings of caterpillar-induced depolarization waves in sieve elements using aphid electrodes. New Phytol. 203, 674-684. doi: $10.1111 /$ nph.12807

Scholz, S. S., Vadassery, J., Heyer, M., Reichelt, M., Bender, K. W., Sneddend, W. A., et al. (2014). Mutation of the arabidopsis calmodulin-like protein CML37 deregulates the jasmonate pathway and enhances susceptibility to herbivory. Mol. Plant 7, 1712-1726. doi: 10.1093/mp/ssu102

Segarra, G., Van der Ent, S., Trillas, I., and Pieterse, C. M. (2012). MYB72, a node of convergence in induced systemic resistance triggered by a fungal and a bacterial beneficial microbe. Plant Biol. 11, 90-96. doi: 10.1111/j.1438-8677.2008.00162.x

Selosse, M. A., Richard, F., He, X., and Simard, S. W. (2006). Mycorrhizal networks, des liaisons dangereuses? Trends Ecol. Evol. 21, 621-628. doi: 10.1016/j.tree.2006.07.003

Simard, S. W., Beiler, K. J., Bingham, M. A., Deslippe, J. R., Philip, L. J., and Teste, F. P. (2012). Mycorrhizal networks: mechanisms, ecology and modelling. Fungal Biol. Rev. 26, 39-60. doi: 10.1016/j.fbr.2012.01.001

Song, Y. Y., Ye, M., Li, C., He, X., Zhu-Salzman, K., Wang, R. L., et al. (2014). Hijacking common mycorrhizal networks for herbivore-induced defence signal transfer between tomato plants. Sci. Rep. 4:3915. doi: 10.1038/srep03915

Song, Y. Y., Zeng, R. S., Xu, J. F., Li, J., Shen, X., and Yihdego, W. G. (2010). Interplant communication of tomato plants through underground common mycorrhizal networks. PLoS ONE 5:e13324. doi: 10.1371/journal.pone.0013324

Staswick, P. E., Su, W. P., and Howell, S. H. (1992). Methyl jasmonate inhibition of root-growth and induction of a leaf protein are decreased in an Arabidopsis thaliana mutant. Proc. Natl. Acad. Sci. U.S.A. 89, 6837-6840. doi: $10.1073 /$ pnas.89.15.6837

Steinhorst, L., and Kudla, J. (2014). Signaling in cells and organisms - calcium holds the line. Curr. Opin. Plant Biol. 22, 14-21. doi: 10.1016/j.pbi.2014.08.003

Sun, C., Shao, Y., Vahabi, K., Lu, J., Bhattacharya, S., Dong, S., et al. (2014). The beneficial fungus Piriformospora indica protects Arabidopsis from Verticillium dahliae infection by downregulation plant defense responses. BMC Plant Biol. 14:268. doi: 10.1186/s12870-014-0268-5

Suzuki, N., and Mittler, R. (2012). Reactive oxygen species-dependent wound responses in animals and plants. Free Radic. Biol. Med. 53, 2269-2276. doi: 10.1016/j.freeradbiomed.2012.10.538

Swanson, S. J., Choi, W. G., Chanoca, A., and Gilroy, S. (2011). In vivo imaging of $\mathrm{Ca} 2+, \mathrm{pH}$, and reactive oxygen species using fluorescent probes in plants. Annu. Rev. Plant Biol. 62, 273-297. doi: 10.1146/annurev-arplant-042110-103832

Teste, F. P., Simard, S. W., and Durall, D. M.: (2009). Role of mycorrhizal networks and tree proximity in ectomycorrhizal colonization of planted seedlings. Fungal Ecol. 2, 21-30. doi: 10.1016/j.funeco.2008.11.003

Torres, M., Dangl, J. L., and Jones, J. D. (2002). Arabidopsis gp91phox homologues AtrbohD and AtrbohF are required for accumulation of reactive oxygen intermediates in the plant defense response. Proc. Natl. Acad. Sci. U.S.A. 99, 517-522. doi: 10.1073/pnas.012452499

Ueda, H., Kikuta, Y., and Matsuda, K. (2012). Plant communication: mediated by individual or blended VOCs? Plant Signal. Behav. 7, 222-226. doi: $10.4161 /$ psb. 18765

Vahabi, K., Camehl, I., Sherameti, I., and Oelmüller, R. (2013). Growth of Arabidopsis seedlings on high fungal doses of Piriformospora indica has little effect on plant performance, stress, and defense gene expression in spite of elevated jasmonic acid and jasmonic acid-isoleucine levels in the roots. Plant Signal. Behav. 8:e26301. doi: 10.4161/psb.26301

Vahabi, K., Sherameti, I., Bakshi, M., Mrozinska, A., Ludwig, A., Reichelt, M., et al. (2015a). The interaction of Arabidopsis with Piriformospora indica shifts from initial transient stress induced by fungus-released chemical mediators to a mutualistic interaction after physical contact of the two symbionts. BMC Plant Biol. 15:58. doi: 10.1186/s12870-015-0419-3

Vahabi, K., Sun, C., Govindaswamy, J., Falkenberg, D., Venus, T., and Oelmüller, R. (2015b). Stomata staining in Arabidopsis. Endocyt. Cell Res. 26, 21-24.

van Bel, A. J. E., Furch, A. C. U., Will, T., Buxa, S. V., Musetti, R., and Hafke, J. B. (2014). Spread the news: systemic dissemination and local impact of $\mathrm{Ca}^{2+}$ signals along the phloem pathway. J. Exp. Bot. 65, 1761-1787. doi: $10.1093 / j x b / e r t 425$

Van der Does, D., Leon-Reyes, A., Koornneef, A., Van Verk, M. C., Rodenburg, N., Pauwels, L., et al. (2010). Salicylic acid suppresses jasmonic acid signaling downstream of SCFCOI1-JAZ by targeting GCC promoter motifs via transcription factor ORA59. Plant Cell 25, 744-761. doi: $10.1105 /$ tpc. 112.108548

van der Ent, S., Verhagen, B. W., Van Doorn, R., Bakker, D., Verlaan, M. G., Pel, M. J., et al. (2008). MYB72 is required in early signaling steps of rhizobacteriainduced systemic resistance in Arabidopsis. Plant Physiol. 146, 1293-1304. doi: 10.1104/pp.107.113829

Venus, Y., and Oelmüller, R. (2013). Arabidopsis ROP1 and ROP6 influence germination time, root morphology, the formation of F-actin bundles, and symbiotic fungal interactions. Mol. Plant. 6, 872-886. doi: 10.1093/mp/sss 101

Verma, S., and Varma, A. (1998). Piriformospora indica, gen. et sp. nov., a new root-colonizing fungus. Mycologia 90, 896-903. doi: 10.2307/3761331

Verma, V., Ravindran, P., and Kumar, P. P. (2016). Plant hormonemediated regulation of stress responses. BMC Plant Biol. 16:86. doi: 10.1186/s12870-016-0771-y

Vlot, A. C., Klessig, D. F., and Park, S. W. (2008). Systemic acquired resistance: the elusive signal(s). Curr. Opin. Plant Biol. 11, 436-442. doi: $10.1016 /$ j.pbi.2008.05.003

Wang, R., Xing, X., Wang, Y., Tran, A., and Crawford, N. M. (2009). A genetic screen for nitrate-regulatory mutants captures the nitrate transporter gene NRT1.1. Plant Physiol. 151, 472-478. doi: 10.1104/pp.109.140434

Wang, T., Campbell, E. M., O’Neill, G. A., and Aitken, S. N. (2012). Projecting future distributions of ecosystem climate niches: uncertainties and management applications. For. Ecol. Manage. 279, 128-140. doi: 10.1016/j.foreco.2012.05.034

White, A. C., Rogers, A., Rees, M., and Osborne, C. P. (2016). How can we make plants grow faster? A source-sink perspective on growth rate. J. Exp. Bot. 67, 31-45. doi: 10.1093/jxb/erv447

Wu, Y., Zhang, D., Chu, J. Y., Boyle, P.,Wang, Y., Brindle, I. D., et al. (2012). The Arabidopsis NPR1 protein is a receptor for the plant defense hormone salicylic acid. Cell Rep. 1, 639-637. doi: 10.1016/j.celrep.2012.05.008

Xuan, W., Beeckman, T., and Xu, G. (2017). Plant nitrogen nutrition: sensing and signaling. Curr. Opin. Plant Biol. 39, 57-65. doi: 10.1016/j.pbi.2017.05.010

Yang, D. L., Yang, Y., and He, Z. (2013). Roles of plant hormones and their interplay in rice immunity. Mol. Plant. 6, 675-685. doi: 10.1093/mp/sst056

Ye, W., Shen, C. H., Lin, Y., Chen, P. J., Xu, X., Oelmüller, R., et al. (2014). Growth promotion-related miRNAs in Oncidium orchid roots colonized by the endophytic fungus Piriformospora indica. PLoS ONE 9:e84920. doi: 10.1371/journal.pone.0084920

Yogawat, A., Saha, S., Bakshi, M., Dayaman, V., Kumar, M., Dua, M., et al. (2013). Piriformospora indica rescues growth diminution of rice seedlings during high salt stress. Plant Signal. Behav. 8:e26891. doi: 10.4161/psb.26891

Zhang, Z.-P., and Baldwin, I. T. (1997). Transport of $\left[2-{ }^{14} \mathrm{C}\right]$ jasmonic acid from leaves to roots mimics wound-induced changes in endogenous jasmonic acid pools in Nicotiana sylvestris. Planta 203, 436-441. doi: 10.1007/s0042500 50211

Zimmermann, M. R., Maischak, H., Mithöfer, A., Boland, W., and Felle, H. H. (2009). System potentials, a novel electrical long-distance apoplastic signal in plants, induced by wounding. Plant Physiol. 149, 1593-1600. doi: $10.1104 /$ pp. 108.133884

Conflict of Interest Statement: The authors declare that the research was conducted in the absence of any commercial or financial relationships that could be construed as a potential conflict of interest.

The reviewer PSB and handling Editor declared their shared affiliation.

Copyright (C) 2018 Vahabi, Reichelt, Scholz, Furch, Matsuo, Johnson, Sherameti, Gershenzon and Oelmüller. This is an open-access article distributed under the terms of the Creative Commons Attribution License (CC BY). The use, distribution or reproduction in other forums is permitted, provided the original author(s) and the copyright owner are credited and that the original publication in this journal is cited, in accordance with accepted academic practice. No use, distribution or reproduction is permitted which does not comply with these terms. 